\title{
Effect of acoustic excitation amplitude on airfoil laminar boundary layer separation and wake development
}

\author{
Serhiy Yarusevych, Pierre E. Sullivan, and John G. Kawall
}

Version Post-print/accepted manuscript

Citation Yarusevych, Serhiy, Pierre E. Sullivan, and John G. Kawall. "Effect of (published version) acoustic excitation amplitude on airfoil boundary layer and wake development." AIAA journal 45, no. 4 (2007): 760-771.

Doi: $\underline{10.2514 / 1.25439}$

How to cite TSpace items

Always cite the published version, so the author(s) will receive recognition through services that track citation counts, e.g. Scopus. If you need to cite the page number of the author manuscript from TSpace because you cannot access the published version, then cite the TSpace version in addition to the published version using the permanent URI (handle) found on the record page.

This article was made openly accessible by $U$ of $T$ Faculty. Please tell us how this access benefits you. Your story matters. 


\title{
Effect of acoustic excitation amplitude on airfoil laminar boundary layer separation and wake development
}

\author{
Serhiy Yarusevych ${ }^{1}$ \\ Department of Mechanical Engineering, University of Waterloo, Waterloo, Canada, N2L \\ Pierre E. Sullivan ${ }^{2}$ \\ Department of Mechanical and Industrial Engineering, University of Toronto, Toronto, Canada, M5S 3G8 \\ John G. Kawall \\ Department of Mechanical and Industrial Engineering, Ryerson University, Toronto, Canada, M5B $2 \mathrm{~K} 3$

\begin{abstract}
The effect of acoustic excitation amplitude on boundary layer and wake development for a NACA 0025 airfoil was studied experimentally at low Reynolds numbers. Flow characteristics were investigated with hot-wire anemometry, surface pressure measurements, and flow visualization. A laminar boundary layer separation occurs on the upper surface of the airfoil for all situations examined. When the flow is excited at the frequency matching the frequency of the most amplified disturbance in the separated shear layer, natural shear- layer disturbances lock onto the excitation frequency, and transition is promoted. If the separated shear layer fails to reattach, an initial increase of the excitation amplitude above a minimum threshold eventually results in shear layer reattachment. The results suggest that an increase of the excitation amplitude not only advances the location of reattachment but also delays boundary layer separation, thereby reducing the extent of the separation region. As a consequence, excitation results in narrowing of the wake and diminishment of the length scales and coherence of the organized wake structures. However, this effect is eventually limited, and a maximum effective excitation amplitude can be identified. It is also
\end{abstract} \\ shown that an increase of the excitation amplitude has a broadly similar effect on flow patterns to an \\ increase of the chord Reynolds number.
}

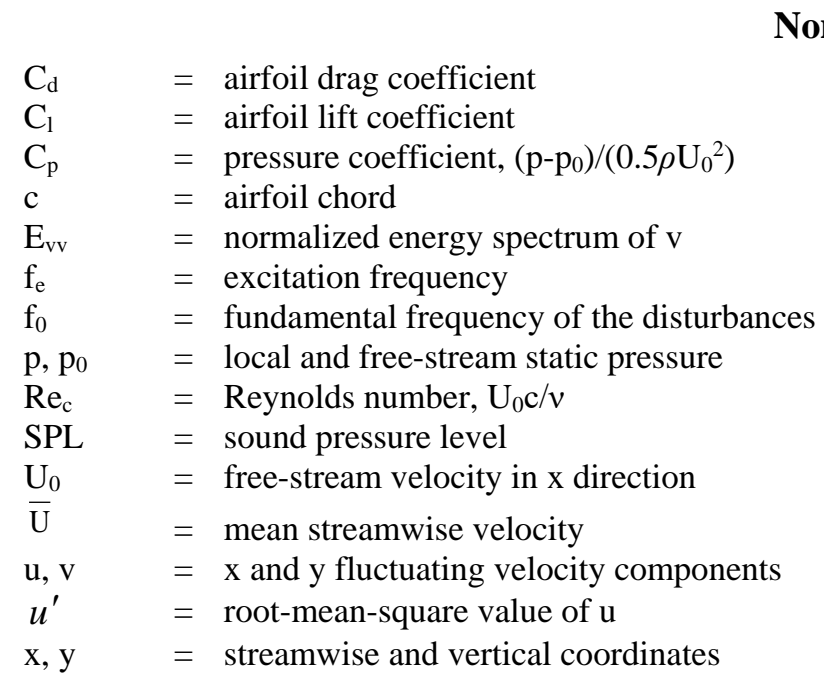

${ }^{1}$ Assistant Professor, Department of Mechanical Engineering, University of Waterloo, 200 University Ave. W, Waterloo, Ontario, Canada, N2L 3G1, AIAA member.

${ }^{2}$ Associate Professor, Department of Mechanical and Industrial Engineering, University of Toronto, 5 King's College Rd., Toronto, M5S 3G8.

${ }^{3}$ Associate Professor, Department of Mechanical and Industrial Engineering, Ryerson University, 350 Victoria St., Toronto, M5B 2K3. 
S. Yarusevych, P. E. Sullivan, and J. G. Kawall, "Effect of acoustic excitation amplitude on airfoil boundary layer and wake development," AIAA J., vol. 45, no. 4, pp. 760-771, 2007. DOI: 10.2514/1.25439

$\alpha \quad=$ angle of attack

$\rho \quad=$ density of air

$v \quad=$ kinematic viscosity of air 


\section{I.Introduction}

EXerimental results suggest that airfoil performance at low Reynolds numbers $\left(\operatorname{Re}_{c}<500,000\right)$ can be significantly affected by laminar boundary layer separation. ${ }^{1}$ In this range of Reynolds numbers, a laminar boundary layer often separates even at low angles of attack, forming a separated shear layer. The rapid transition to turbulence that occurs in the separated shear layer can lead to the latter's reattachment and the formation of a separation bubble. On the other hand, at lower Reynolds numbers, the separated shear layer fails to reattach to the airfoil surface and a wide turbulent wake is formed. In both cases, laminar boundary layer separation results in a significant degradation of airfoil performance, adversely affecting airfoil lift and drag.

Several studies have demonstrated that introduction of either external or internal periodic excitation, e.g., acoustic waves, at an appropriate frequency and amplitude can improve airfoil performance that is adversely affected by laminar separation. ${ }^{2-}$ ${ }^{12}$ In the case of external excitation ${ }^{3-10}$, acoustic waves are generated by a remote source; whereas, for internal excitation ${ }^{9-12}$, periodic disturbances are introduced directly into the boundary layer, e.g., from a slot in the airfoil surface. For both types of excitation, it has been shown that the effect depends strongly on the excitation frequency and amplitude. However, experimental attempts to predict optimum parameters of the excitation and explain the process responsible for the control result in a wide range of sometimes contradictory conclusions. ${ }^{4}$

Previous experiments were focused mostly on establishing the optimum excitation frequency. These studies provide similar findings for both external and internal excitation within two ranges of the angle of attack. At angles of attack below and in the vicinity of the stall angle, common for most applications, Nishioka et al. ${ }^{6}$, Zaman and McKinzie ${ }^{7}$, and Hsiao et al. ${ }^{11}$, suggested that the optimum effect occurs when the excitation frequency matches the instability frequency of the separated shear layer. Recently, Yarusevych et al. ${ }^{8,9}$ established a clear correlation between the optimum excitation frequency and the frequency of the most amplified disturbance in the unexcited separated shear layer. It was suggested that periodic excitation at that frequency promotes boundary layer transition, causing earlier boundary layer reattachment. On the other hand, at high post stall angles of attack, Hsiao et al. ${ }^{11}$ have found that the most effective excitation frequency of internal forcing matches the vortex shedding frequency in the airfoil wake. This is in agreement with the result reported by Zaman ${ }^{4}$, who used external excitation. Zaman ${ }^{4}$ observed that an increase of excitation amplitude shifts optimum effect to lower excitation frequencies that appear to correlate with the vortex shedding frequencies.

It has been shown that the extent of the effective frequency range and the effect of excitation strongly depend on the excitation amplitude. ${ }^{12}$ Results obtained by Ahuja and Burrin ${ }^{10}$ suggest that, above a minimum threshold level, an increase of the excitation amplitude is associated with an increase in the airfoil lift. Previous investigations also show that, as angle of 
attack increases, higher excitation amplitudes are required to produce appreciable effect on airfoil characteristics. In such situations when high excitation amplitude is required, wind tunnel resonance has been reported to influence the results. ${ }^{7}$ It should be noted that internal excitation usually requires smaller excitation amplitude compared to external excitation. However, efficiency of the flow control with internal excitation depends strongly on the location and the orientation of the slot, with the optimum configuration of these two parameters remaining uncertain. ${ }^{3}$

Despite significant insight produced by several studies into the active flow control of laminar boundary layer separation, the attendant flow control mechanism is not fully understood. In particular, the effect of excitation amplitude on flow transition and wake characteristics has not been investigated in detail. 'Small' amplitude artificial disturbances are sometimes used to create controlled conditions in the studies of flow transition in laminar separation bubbles. ${ }^{13}$ However, 'high' amplitude forcing has been shown to alter the development of excited flow instabilities. ${ }^{14}$ It has been speculated by Boiko et al. ${ }^{15}$ that an increase of excitation amplitude can change the attendant transition mechanism.

The limited insight gained in previous studies into the effect of excitation amplitude can be attributed in part to the uncertainty associated with the choice of the optimum excitation parameters and a number of other control factors involved in various control techniques. In the light of this, the current experimental investigation was undertaken to examine the effect of excitation amplitude on flow development in both boundary layer and airfoil wake for external acoustic excitation. This control method serves to minimize the number of control parameters involved, with the excitation frequency and amplitude being the primary control parameters. Furthermore, with correlations for the optimum excitation frequency reported by Yarusevych et al. ${ }^{8,9}$, it is possible to isolate the excitation amplitude as a single control factor.

\section{II.Experimental Description}

All experiments were performed in a low-turbulence recirculating wind tunnel. The 5-m-long octagonal test section of this tunnel has a spanwise extent of $0.91 \mathrm{~m}$ and a height of $1.22 \mathrm{~m}$. The flow enters the test section through seven screens and a 9:1 contraction. The free-stream velocity $\left(\mathrm{U}_{0}\right)$ is adjustable from $2.8 \mathrm{~m} / \mathrm{s}$ to $18 \mathrm{~m} / \mathrm{s}$, with a background turbulence intensity level less than $0.1 \%$. During the experiments, the free-stream velocity was monitored by a pitot tube, with an uncertainty estimated to be less than $2.5 \%$.

The performance of a symmetrical NACA 0025 aluminum airfoil with a chord length (c) of $0.3 \mathrm{~m}$ and a span of $0.88 \mathrm{~m}$ was examined. A schematic of the tunnel test section is shown in Fig. 1. The airfoil was mounted horizontally in the test section $0.4 \mathrm{~m}$ downstream of the contraction. Mean-flow uniformity over at least $50 \%$ of the airfoil span was verified via hotwire measurements. Sound excitation was provided by means of two 50W loudspeakers mounted above and below the airfoil (Fig. 1), with their downstream position approximately corresponding to the location of the minimum surface pressure on the 
upper surface of the airfoil. Two loudspeakers were used to provide a more uniform acoustic field in the test section. The speakers were driven through an amplifier by a variable-frequency wave generator. The loudspeaker were placed to minimize structural vibrations, and it was verified from accelerometer measurements that, within the frequency range of interest $\left(f_{e}<\right.$ $550 \mathrm{~Hz}$ ), surface vibrations are sufficiently low for their effect on flow characteristics to be neglected. ${ }^{9}$ Thus, at $\mathrm{f}_{\mathrm{e}}<550 \mathrm{~Hz}$, flow excitation can be considered to be purely acoustic. A microphone was employed to quantify sound excitation on the upper surface of the airfoil. Based on the instrument precision for a frequency range of $40 \mathrm{~Hz}$ to $1000 \mathrm{~Hz}$, the uncertainty of the microphone measurements is approximately $\pm 0.3 \mathrm{~dB}$. For the investigated flow control parameters, reasonably uniform (within 3\%) spanwise sound pressure distribution was produced over at least 50\% of the central span on the upper surface of the airfoil within the area corresponding to the transition region for the cases examined.

Velocity data were obtained with constant temperature anemometers. A normal hot-wire probe and a cross-wire probe were used. The probes were mounted on a remotely controlled traversing gear, which allowed probe motion in the vertical (y) and streamwise (x) directions with a resolution of $0.01 \mathrm{~mm}$ and $0.25 \mathrm{~mm}$, respectively. All hotwire measurements were carried out in the vertical midspan plane of the tunnel, with the origin of the coordinate system located at the leading edge of the airfoil. Based on the results of Kawall et al. ${ }^{16}$, the maximum hot-wire measurement error was estimated to be less than 5\% and is attributed to the high turbulent intensities in the separated shear layer and near wake.

For spectral analysis of the velocity signals, sampled at $5000 \mathrm{~Hz}$, the duration of a sampled signal segment was sufficiently large to provide a frequency resolution bandwidth of $0.6 \mathrm{~Hz}$, adequate for resolving narrow peaks in the spectrum. Based on the number of averages involved in obtaining the velocity spectra, the uncertainty of the spectral analysis was estimated to be approximately $4.5 \%$. All presented spectra are normalized by the variance of the sampled velocity signal, so that the area under the spectral curve is unity. To allow adequate comparison of the spectra, ${ }^{17}$ velocity data intended for spectral analysis were obtained at $\mathrm{y} / \mathrm{c}$ positions corresponding to $0.5 \mathrm{U}_{0}$ in the separated shear layer $(\mathrm{x} / \mathrm{c} \leq 1)$ and to half of the maximum velocity deficit in the airfoil wake $(x / c>1)$. Spectral analysis of the free-stream velocity signals established that there was no significant frequency-centred activity associated with the approach flow.

The airfoil was equipped with 65 pressure orifices, which were positioned at the midspan symmetrically on the upper and lower surfaces. Surface pressure measurements were conducted via a pressure transducer and a Scanivalve module, with the associated uncertainty of less than $2 \%$.

The effect of acoustic excitation on airfoil performance was assessed based on the lift and drag coefficients. The lift coefficient $\left(\mathrm{C}_{1}\right)$ was determined by integrating the mean surface pressure distribution; whereas, the drag coefficient $\left(\mathrm{C}_{\mathrm{d}}\right)$ was calculated based on the momentum integral, using wake velocity profiles obtained at $\mathrm{x} / \mathrm{c}=2$. The uncertainty for the lift coefficient was estimated to be less than $4 \%$ and that for the drag coefficient less than $7 \%$. 
To visualize airfoil boundary layer development and wake formation, a smoke wire technique was employed. A smoke wire installed $15 \mathrm{~cm}$ upstream of the leading edge was coated with smoke-generator fluid. The fluid was evaporated by inductively heating the wire, producing clear streaklines in the flow. A thin $0.076 \mathrm{~mm}$ diameter wire (304 stainless steel) was chosen in order to provide adequate smoke density, while avoiding the introduction of measurable disturbances into the flow field, with the corresponding Reynolds numbers being less than 40 for all situations examined. The flow was illuminated with a remotely triggered speedlight, and the images were acquired with a Nikon D70s digital camera.

\section{III.Results}

\section{A. Unexcited Flow Characteristics}

The airfoil was studied for a range of chord Reynolds numbers $\left(\operatorname{Re}_{c}\right)$ and several angles of attack $(\alpha)$. To illustrate boundary layer and wake development in the unexcited flow, flow visualization results for $\operatorname{Re}_{\mathrm{c}}=100 \times 10^{3}$ and $\operatorname{Re}_{\mathrm{c}}=150 \times 10^{3}$ at $\alpha=5^{\circ}$ are shown in Fig. 2. For $\mathrm{Re}_{\mathrm{c}}=100 \times 10^{3}$ (Fig. 2a), the boundary layer separates on the upper surface of the airfoil and fails to reattach. This leads to the formation of a wide wake, with large-scale vortical structures developing in the near wake region. As the Reynolds number is increased to $\mathrm{Re}_{\mathrm{c}}=150 \times 10^{3}$ (Fig. 2b), boundary layer behaviour and wake development change dramatically. A separation bubble forms on the upper surface of the airfoil, resulting in a narrower wake for this Reynolds number compared to that for $\mathrm{Re}_{\mathrm{c}}=100 \times 10^{3}$. In addition, vortical structures that form in the wake region are associated with smaller length scales and are less coherent than those observed for the lower Reynolds number.

One distinctive characteristic of boundary layer separation is the region of nearly constant static pressure downstream of the separation point. ${ }^{1}$ If the separated shear layer fails to reattach, the constant-pressure region extends to the trailing edge of the airfoil. On the other hand, a sudden increase in pressure following the constant-pressure region serves to indicate transition in the separated shear layer, which leads to boundary layer reattachment and the formation of a separation bubble. As shown by Tani, ${ }^{18}$ the location of the reattachment point can be estimated as the position where the pressure reaches the value found in the absence of boundary layer separation. This value can be approximated by means of an inviscid flow solution. Therefore, the presence and the extent of the separation region can be assessed from a surface pressure distribution.

The effect of Reynolds number on the airfoil boundary layer behaviour is depicted in Fig. 3, which shows distributions of the surface pressure coefficient $\left(\mathrm{C}_{\mathrm{p}}\right)$ for a range of Reynolds numbers at $\alpha=5^{\circ}$. The estimated positions of separation, transition and reattachment on the upper surface of the airfoil are marked by $\mathbf{S}, \mathbf{T}$, and $\mathbf{R}$, respectively. It should be noted that transition occurs over an extended region, rather than being localized at a transition 'point', thus, the identified locations approximately mark the onset of non-linear stage of transition. ${ }^{13} \mathrm{For}_{\mathrm{c}}=200 \times 10^{3}$, a short separation bubble is formed on the upper surface between $\mathrm{x} / \mathrm{c}=0.45$ and 0.62 (Fig. 3a). A separation bubble also develops on the lower surface of the airfoil, extending from 
approximately $\mathrm{x} / \mathrm{c}=0.6$ to 0.75 . As the Reynolds number decreases to $150 \times 10^{3}$ (Fig. $3 \mathrm{~b}$ ), the separation bubble on the upper surface of the airfoil broadens slightly, located between $\mathrm{x} / \mathrm{c}=0.4$ and 0.66 , resulting in a diminishment of the suction peak. Further decrease of the Reynolds number brings about significant changes in the boundary layer development and characteristics. For $\operatorname{Re}_{\mathrm{c}}=143 \times 10^{3}$ (Fig. 3c), the boundary layer on the upper surface separates at approximately $\mathrm{x} / \mathrm{c}=0.35$ and fails to reattach, despite evidence of transition, marked by a mild pressure recovery past $\mathrm{x} / \mathrm{c}=0.55$. The attendant abrupt increase in the size of the separation region is associated with bubble bursting and results in a significant reduction of the suction peak on the upper surface. As was determined based on time-resolved surface pressure measurements (not presented here), this inherently unstable process takes place over a short range of Reynolds numbers and is accompanied by intermittent flow reattachment. Eventually, for $\operatorname{Re}_{\mathrm{c}}=100 \times 10^{3}$ (Fig. 3d), the boundary layer on the upper surface separates at $\mathrm{x} / \mathrm{c}=0.3$, forming a wake.

Transition that occurs in the separated shear layer plays an important role in flow development, as it can lead to boundary layer reattachment and the formation of a separation bubble. ${ }^{1}$ It has been shown ${ }^{17}$ that a similar transition mechanism is attendant in the cases of boundary layer separation without reattachment and when a separation bubble forms on the airfoil surface. Specifically, disturbances within a band of frequencies, centred at a fundamental frequency $\left(\mathrm{f}_{0}\right)$, are amplified in the separated shear layer. This is depicted in Fig. 4, which shows spectra $\left(\mathrm{E}_{\mathrm{vv}}\right)$ of the vertical fluctuating velocity component (v) for $\operatorname{Re}_{\mathrm{c}}=100 \times 10^{3}$ and $\operatorname{Re}_{\mathrm{c}}=150 \times 10^{3}$ at $\alpha=5^{\circ}$. The spectral results reveal clear peaks centred at the fundamental frequency and its harmonics. For $\operatorname{Re}_{\mathrm{c}}=100 \times 10^{3}$, a band of unstable Fourier components occurs centred at a fundamental frequency $\mathrm{f}_{0} \approx 165$ $\mathrm{Hz}$. The spectral results pertaining to $\mathrm{Re}_{\mathrm{c}}=150 \times 10^{3}$ indicate that the peak is centred at a higher value of $\mathrm{f}_{0} \approx 455 \mathrm{~Hz}$ for this Reynolds number. The initial growth of the disturbances is followed by the generation and growth of a sub-harmonic of the fundamental frequency, leading to a laminar-to-turbulent transition. More details on airfoil boundary layer and turbulent wake development within the presented range of Reynolds numbers can be found in Ref. 17.

\section{B. Control Parameters}

A detailed investigation of the effect of acoustic excitation on flow characteristics was conducted for the two distinctly different boundary layer regimes, viz., (1) boundary layer separation without reattachment (i.e., when separated shear layer fails to reattach, forming a wake) and (2) separation bubble formation, that occur when $\operatorname{Re}_{c}=100 \times 10^{3}$ and $\operatorname{Re}_{c}=150 \times 10^{3}$ at $\alpha=5^{\circ}$.

Wind tunnel resonance characteristics were examined at $\mathrm{U}_{0}=0$. A microphone, positioned $40 \mathrm{~mm}$ above the upper airfoil surface, at $\mathrm{x} / \mathrm{c}=0.5$ and in the midspan of the airfoil, was used to measure sound pressure. This downstream position approximately corresponds to the location of the transition region for the cases examined. The measurements were conducted 
for various excitation frequencies and constant voltage input to the loudspeakers. The variation of sound pressure level (SPL) with excitation frequency is shown in Fig. 5. The analysis of resonance frequencies in the test section suggests that, within the investigated frequency range, the distinct peaks in Fig. 5 are associated with tangential and oblique modes. In particular, dominant peaks occurring at about $405 \mathrm{~Hz}$ and $610 \mathrm{~Hz}$ are attributed to cross-resonances within the test section.

Based on the results reported by Yarusevych et al. ${ }^{8,9}$, the optimum frequency for flow control with periodic excitation should match the frequency of the most amplified disturbances in the separated shear layer. As the separated shear layer develops downstream, amplification of the disturbances within the frequency band centred at the fundamental frequency leads to boundary layer transition. Thus, exciting the boundary layer at the fundamental frequency promotes transition and can result in boundary layer reattachment, thereby improving airfoil performance. For the investigated flow characteristics, fundamental frequencies were determined via spectral analysis of velocity signals obtained in the unexcited separated shear layer (Fig. 4). It should be noted that the identified fundamental frequencies in Fig. 4 do not match the dominant resonance frequencies in Fig. 5.

The effect of acoustic excitation applied at a sufficiently large amplitude (SPL > $100 \mathrm{~dB}$ ) and at the excitation frequency $\left(\mathrm{f}_{\mathrm{e}}\right)$ matching the fundamental frequency is illustrated by the flow visualization results presented in Figs. 6 and 7, which pertain to $\operatorname{Re}_{\mathrm{c}}=100 \times 10^{3}$ and $\operatorname{Re}_{\mathrm{c}}=150 \times 10^{3}$, respectively, at $\alpha=5^{\circ}$. For the case of boundary separation without reattachment, i.e., for $\mathrm{Re}_{\mathrm{c}}=100 \mathrm{x} 10^{3}$ (Fig. 6), acoustic excitation effects boundary layer reattachment and a separation bubble forms on the upper surface. Evidently, this results in a dramatic reduction of the airfoil wake. Specifically, wake vortices are suppressed by the periodic excitation and are replaced by smaller coherent structures. In contrast, the flow control produces less significant effect for $\operatorname{Re}_{c}=150 \times 10^{3}$ (Fig. 7). In this case, a separation bubble is present in the unexcited flow; and the bubble can only be reduced in size marginally by acoustic excitation, which would not lead to dramatic changes in flow characteristics.

\section{Effect of Excitation Amplitude}

With the optimum excitation frequencies having been established, the effect of the single remaining control parameter on airfoil performance - the excitation amplitude - was studied. The excitation amplitude was quantified by sound pressure measurements conducted at the reference location above the upper surface of the airfoil in the absence of incoming flow (Fig. 5). The background noise level in the tunnel test section was measured to be approximately $70.4 \mathrm{~dB}$ and $72.6 \mathrm{~dB}$ for $\operatorname{Re}_{c}=100 \times 10^{3}$ and $\operatorname{Re}_{c}=150 \times 10^{3}$, respectively. The total sound pressure level obtained by adding the background noise level to the SPL produced solely by acoustic excitation was used to characterize the excitation amplitude. Also, it was verified that the acoustic streaming effect was negligible in the present investigation. 
Figure 8 shows distributions of the surface pressure coefficient $\left(\mathrm{C}_{\mathrm{p}}\right)$ obtained at various excitation amplitudes for $\operatorname{Re}_{c}=100 \times 10^{3}$ at $\alpha=5^{\circ}$. Without flow control, a constant pressure region on the upper surface of the airfoil, which indicates the extent of the separation region, stretches over the aft $70 \%$ percent of the chord (Fig. 8a). The initial increase of the excitation amplitude results in an intermittent boundary layer reattachment, with substantial surface pressure fluctuations observed during the experiments (not shown). Eventually, a reattachment is obtained at an SPL of $80.1 \mathrm{~dB}$, and a laminar separation bubble is formed in the mid-chord region (Figs. 8b). Further increase of the excitation amplitude results in a minor reduction of the separation bubble on the upper surface of the airfoil and also effects reattachment of the separated shear layer on the lower surface close to the trailing edge (Figs. 8c-8d). Results for $\operatorname{Re}_{c}=150 \times 10^{3}$ at $\alpha=5^{\circ}$ presented in Fig. 9 indicate that the extent of the separation bubble on the upper surface of the airfoil is gradually reduced with an increase of excitation amplitude. Specifically, as excitation amplitude increases, boundary layer separation occurs farther downstream, a constant-pressure region shrinks and is followed by a more rapid pressure recovery, and the reattachment location advances upstream. It is interesting to note that acoustic excitation at high amplitudes results in boundary layer reattachment on the lower surface of the airfoil for $\operatorname{Re}_{\mathrm{c}}=100 \times 10^{3}$ (Fig. 8) but does not substantially affect the separation bubble on the lower surface for $\operatorname{Re}_{\mathrm{c}}=150 \times 10^{3}$ (Fig. 9). The limited effect observed for $\mathrm{Re}_{\mathrm{c}}=150 \times 10^{3}$ was verified to be attributed to a substantial discrepancy between the excitation frequency and the fundamental frequency of the disturbances developing in the separated shear layer on the lower surface of the airfoil.

A comparison of the surface pressure distributions presented for the two Reynolds numbers reveals the similarity between the respective surface pressure distributions obtained at higher amplitude levels, for example, as seen from the comparison of Fig. 8d and Fig. 9d. Also, surface pressure distributions obtained at high amplitude excitation resemble those observed in unexcited flows at higher Reynolds numbers (Fig. 3). To investigate this further, several pressure distributions pertaining to the upper surface are presented in Fig. 10. Figure 10a depicts the effect of Reynolds number, while Fig. 10b illustrates the effect of excitation amplitude for $\mathrm{Re}_{\mathrm{c}}=100 \times 10^{3}$. Evidently, similar trends are observed in Figs. 10a and 10b. Specifically, an increase of either the Reynolds number or excitation amplitude delays boundary layer separation and eventually leads to boundary layer reattachment. Also, when a separation bubble forms on the airfoil surface, a more pronounced pressure recovery occurs in the aft portion of the bubble for both cases, indicating a more rapid transition and a shorter distance to reattachment. ${ }^{1,18}$

A quantitative analysis of the effect of excitation amplitude on airfoil characteristics is based on the results presented in Fig. 11, which shows the variation of the airfoil lift and drag coefficients with sound pressure level for $\operatorname{Re}_{\mathrm{c}}=100 \times 10^{3}$ and $\operatorname{Re}_{\mathrm{c}}=150 \times 10^{3}$ at $\alpha=5^{\circ}$. The first point in each dataset corresponds to the unexcited flow, with the sound pressure level equal 
to the background noise level. Note that, in agreement with the flow visualization results and the surface pressure measurements, the lift coefficient in the unexcited flow is negative for $\mathrm{Re}_{\mathrm{c}}=100 \mathrm{x} 10^{3}$. Such behaviour may occur on relatively thick profiles at low Reynolds numbers and was reported for several symmetrical airfoils. ${ }^{19,20}$ Results presented in Fig. 11a suggest that the excitation amplitude has a significant effect on the airfoil lift coefficient. Based on the experimental observations, it was concluded that excitation applied below a certain SPL did not result in any improvement in the airfoil lift, in agreement with the findings of Ahuja \& Burrin ${ }^{10}$. It was determined that this minimum effective amplitude approximately corresponds to the background noise level in the test section. For $\mathrm{Re}_{\mathrm{c}}=100 \mathrm{x} 10^{3}$, a dramatic increase of the lift coefficient is observed when the acoustic excitation results in boundary layer reattachment and the formation of a separation bubble at SPL $\approx 80 \mathrm{~dB}$. Further increase of the sound pressure level results in a moderate increase of the lift coefficient in Fig. 11a. Finally, once boundary layer reattachment is effected, an increase of the excitation amplitude above an SPL of $90 \mathrm{~dB}$ produces only a minor increase in the lift coefficient. For $\mathrm{Re}_{\mathrm{c}}=150 \times 10^{3}$, an increase of the excitation amplitude above the background noise level results in a moderate increase of the lift coefficient, as acoustic excitation reduces the size of the separation bubble on the upper surface. For both Reynolds number, no hysteresis was observed in the lift coefficient with an increase of decrease of the excitation amplitude. The variation of the airfoil drag coefficient with excitation amplitude (Fig. 11b) displays similar trends to those observed for the lift coefficient. However, in this case, no substantial decrease in the drag coefficient is observed for $\operatorname{Re}_{\mathrm{c}}=100 \times 10^{3}$ at an SPL value below $75 \mathrm{~dB}$, as the excitation does not significantly alter the separation region. As the excitation amplitude is increased above $75 \mathrm{~dB}$ for this Reynolds number, the drag is reduced dramatically, with the increase of SPL above $85 \mathrm{~dB}$ producing a more gradual reduction of the drag coefficient. Note that, at high amplitude excitations (SPL > $90 \mathrm{~dB}$ ), comparable lift and drag coefficients are obtained for both Reynolds numbers examined.

The results presented in Fig. 11 indicate that the positive effect produced by the increase of the excitation amplitude on the airfoil lift and drag is eventually checked. From a practical point of view, it is important to consider the power required to produce excitation at high amplitudes. For the present experimental set-up, an increase of SPL above $80 \mathrm{~dB}$ is associated with an exponential increase of the electric power required to implement the control. A comparison of the lift coefficient and the associated power input (Fig. 12) shows that an increase of the excitation amplitude above a certain SPL may be inefficient, as the potential improvement of the airfoil performance does not justify the required power input. Thus, it is reasonable to identify a maximum efficient excitation amplitude. The precise value of this amplitude can be determined based on the specific design objectives imposed on a given active flow control method. Therefore, two threshold levels for excitation amplitude are identified: (i) a minimum excitation amplitude required to improve airfoil performance that depends on the background noise level, and (ii) a maximum excitation amplitude that represents an efficient limit for the amplitude increase, with further amplitude increase producing only a moderate effect. 
It is instructive to consider the effect of the excitation amplitude on both boundary layer and wake characteristics. Figure 13 depicts the effect of excitation amplitude on mean and RMS velocity profiles in the separated region for $\operatorname{Re}_{\mathrm{c}}=100 \mathrm{x} 10^{3}$ at $\alpha=5^{\circ}$. Mean velocity profiles shown in Fig. 13a suggest that the increase of the excitation amplitude results in a decrease of the vertical extent of the separation region. From the RMS profiles presented in Fig. 13b, it is evident that the intermittent boundary layer reattachment produced at an SPL of $80.1 \mathrm{~dB}$ is associated with an increase in turbulence intensities at this streamwise location. But once the steady boundary layer reattachment is effected (SPL=94.3dB), an increase of excitation amplitude results in a diminishment of turbulence intensities. For $\operatorname{Re}_{c}=150 \times 10^{3}$ at $\alpha=5^{\circ}$ (Fig. 14), an increase of the excitation amplitude also results in a diminishment of the separation region height and the maximum turbulence intensity. For this Reynolds number, RMS profiles develop three distinct maxima at high excitation amplitudes, similar to the findings of Haggmark et al. ${ }^{21}$ for an unexcited separation bubble on a flat plate in an adverse pressure gradient. Since the amplification of the disturbances occurs in the separated shear layer, the fact that an increase of excitation amplitude results in a decrease of turbulence intensities at a given downstream location implies that the separation location has been shifted downstream, in agreement with the surface pressure measurements (Figs. 8, 9, and 10). It is concluded that, once reattachment is effected, further increase of the excitation amplitude not only results in earlier reattachment but also delays boundary layer separation, i.e., the separation bubble shrinks. This phenomenon is attributable to the influence of the transition process in the aft portion of the separation bubble on the upstream laminar boundary layer, which allows the attached laminar boundary layer to withstand the adverse pressure gradient longer. A similar 'feedback mechanism' is discussed by Dovgal et al. ${ }^{13}$, who reported that a reattaching flow can influence the upstream part of the separation bubble.

To understand the effect of the excitation amplitude on the transition process in the boundary layer, spectra of the vertical fluctuating velocity component were obtained. These are shown in Fig. 15, with all spectra acquired within the transition region $(\mathrm{x} / \mathrm{c}=0.59)$. For clarity, the amplitude of each successive spectrum is stepped by two orders of magnitude. As was discussed previously, in the unexcited flow, a transition process in the separated shear layer starts with the natural linear growth of the disturbances around the fundamental frequency. In the case of $\operatorname{Re}_{c}=100 \times 10^{3}$ at $\alpha=5^{\circ}$, two peaks centred at $\mathrm{f}_{0}=165 \mathrm{~Hz}$ and $0.5 \mathrm{f}_{0}$ are evident in the spectrum (Fig. 15a). The generation of a sub-harmonic (cf. Fig. 4 and Fig. 15a) is associated with non-linear effects that lead to a rapid breakdown to turbulence. ${ }^{17}$ With the application of the flow control and an initial increase of the excitation amplitude to $80.1 \mathrm{~dB}$, a narrower and better defined peak at the fundamental frequency is observed in the corresponding spectrum compared to that in the unexcited flow spectrum; also, the sub-harmonic peak is diminished. The implication here is that growing shear layer disturbances within a band of frequencies around the fundamental frequency $\left(\mathrm{f}_{0}\right)$ lock onto the excitation frequency $\left(\mathrm{f}_{\mathrm{e}}=\mathrm{f}_{0}\right)$, producing more coherent shear layer fluctuations. Further increase 
of the excitation amplitude leads to the development of several peaks at higher harmonics and a sub-harmonic peak is not observed at and beyond $\mathrm{SPL}=94.3$. For $\operatorname{Re}_{\mathrm{c}}=150 \times 10^{3}$ at $\alpha=5^{\circ}$ (Fig. $15 \mathrm{~b}$ ), a similar effect is observed but more distinct peaks are produced at harmonics of the excitation frequency. The appearance of stronger harmonics at higher excitation amplitudes is attributed to the presence of more coherent amplified disturbances in the separated shear layer, as evidenced by strong peaks centred at the fundamental frequency in the corresponding spectra.

It is evident from the changes in the discussed velocity spectra (Fig. 15) that the transition process is altered by highamplitude excitation. The analysis of the presented boundary layer measurements reveals the following control mechanism. When acoustic excitation is applied at the optimum frequency and sufficient amplitude, natural shear layer disturbances lock onto the excitation frequency. The excitation promotes the growth of the disturbances and the transition occurs closer to the separation point compared to an unexcited flow. In the case when boundary layer separation occurs without reattachment, an increase of the excitation amplitude eventually effects a separation bubble formation. Once a separation bubble is present on the airfoil surface, increasing the excitation amplitude results in a gradual reduction of the separation bubble. Moreover, by influencing boundary layer transition via the feedback mechanism discussed above, excitation modifies the laminar portion of the separated shear layer and delays the boundary layer separation. As a result, an overall reduction of the separation region is produced, leading to an improvement of airfoil performance.

The effect of excitation amplitude on the wake structure is now considered. Figures 16 and 17 are the mean and RMS wake velocity profiles at various excitation levels at $\alpha=5^{\circ}$ for $\mathrm{Re}_{\mathrm{c}}=100 \times 10^{3}$ and $\mathrm{Re}_{\mathrm{c}}=150 \times 10^{3}$, respectively. The results suggest that the increase of the excitation amplitude is associated with the decrease of both the wake width and turbulence intensities. For $\operatorname{Re}_{\mathrm{c}}=100 \times 10^{3}$, this effect diminishes at SPL $>84.7 \mathrm{~dB}$ (Fig. 16), once boundary layer reattachment is produced. Moreover, for this Reynolds number, the position of the maximum velocity deficit shifts downward and double-peak RMS profiles, common to a near-wake region, appear at higher excitation levels. As in the case of the boundary layer measurements, wake profiles obtained for $\operatorname{Re}_{\mathrm{c}}=100 \times 10^{3}$ (Fig. 16) at higher excitation levels are comparable to those obtained for $\operatorname{Re}_{\mathrm{c}}=150 \times 10^{3}$ (Fig. 17).

Wake velocity spectra presented in Fig. 18 show the effect of excitation amplitude on the coherent structures forming in the airfoil wake. Again, the amplitude of each successive spectrum is stepped by two orders of magnitude. For $\operatorname{Re}_{\mathrm{c}}=100 \mathrm{x} 10^{3}$ (Fig. 18a), a peak in the unexcited flow spectrum centred at approximately $20 \mathrm{~Hz}$ is attributable to wake vortex shedding. The increase of the excitation amplitude above the background noise level results in broadening of this peak and the peak itself is shifted to higher frequencies. This indicates that vortices in the airfoil wake are being replaced by organized structures of smaller length scale and coherence, in agreement with the flow visualization results. For $\operatorname{Re}_{c}=150 \times 10^{3}$ (Fig. 18b), a much 
broader peak in the unexcited flow spectrum than that observed for the lower Reynolds number is shifted from approximately $68 \mathrm{~Hz}$ to higher frequencies with an increase of the excitation amplitude. Note the peak in the spectrum for $\operatorname{Re}_{\mathrm{c}}=100 \times 10^{3}$ at $\mathrm{SPL}=94.3 \mathrm{~dB}$ is centred at approximately the same frequency and has a similar energy distribution as that in the unexcited flow spectrum for $\operatorname{Re}_{\mathrm{c}}=150 \times 10^{3}$.

From these results, it is evident that there is a broad similarity between the effects produced on the flow characteristics by the increase of the excitation amplitude and the increase of the chord Reynolds number. In particular, the comparison of the flow visualization results for $\operatorname{Re}_{\mathrm{c}}=100 \times 10^{3}$ with acoustic excitation (Fig. 6b) and for $\operatorname{Re}_{\mathrm{c}}=150 \times 10^{3}$ in the unexcited flow (Fig. 7a) at $\alpha=5^{\circ}$ shows a notable similarity of the flow patterns in the corresponding images. Also, similar trends are evident in the pressure distributions (Fig. 10) produced as a result of either applying acoustic excitation or increasing the Reynolds number. Finally, these observations are supported by the corresponding wake velocity profiles (cf. Fig. 16 and Fig. 17) and wake velocity spectra (cf. Fig. 18a and Fig. 18b). A more detailed analysis of the observed similarity between the two effects calls for an in-depth study involving various types of airfoils, as this analogy can be used to estimate the effect of various separation control techniques involving periodic excitation on flow characteristics.

\section{IV.Concluding Remarks}

This study focuses on the effect of excitation amplitude on boundary layer and turbulent wake development for a NACA 0025 airfoil at low Reynolds numbers. To minimize the number of control parameters involved, the flow was excited by external acoustic excitation, for which the excitation frequency and amplitude are the main control parameters. Detailed results are presented for $\mathrm{Re}_{\mathrm{c}}=100 \times 10^{3}$ and $\mathrm{Re}_{\mathrm{c}}=150 \times 10^{3}$ at $\alpha=5^{\circ}$, as they represent two distinctly different flow regimes. A laminar boundary layer separation on the upper surface occurs for both Reynolds numbers without excitation. In the case of $\operatorname{Re}_{c}=100 \times 10^{3}$, the boundary layer fails to reattach and a wide turbulent wake forms; whereas, for $\mathrm{Re}_{\mathrm{c}}=150 \times 10^{3}$, the boundary layer reattaches to the airfoil surface and forms a separation bubble, with an attendant narrow turbulent wake.

By applying acoustic excitation at the excitation frequency matching the frequency of the most amplified disturbance in the separated shear layer, new insight was gained into the effect of the excitation amplitude on flow characteristics. Two threshold levels for excitation amplitude were identified. An excitation above a minimum amplitude, which is linked to the background noise level, is required to influence airfoil performance. The analysis of the results reveals that acoustic excitation applied at the optimum frequency and sufficient amplitude promotes flow transition by enhancing the growth and coherence of natural disturbances in the separated shear layer. In the case when boundary layer separation occurs without reattachment, an increase of the excitation amplitude above the minimum threshold eventually leads to a separation bubble formation. By enhancing flow transition, excitation also modifies the laminar portion of the separated shear layer and delays the boundary 
layer separation. Thus, an overall shortening of the separation region and narrowing of the airfoil wake are produced for both Reynolds numbers examined, bringing about an increase in the lift and decrease in the drag. However, once a separation bubble is formed on the airfoil surface, the positive effect produced by an increase of the excitation amplitude gradually diminishes for both Reynolds numbers and a maximum efficient amplitude can be identified for a given application.

The results show that, by altering boundary layer characteristics, acoustic excitation significantly affects airfoil wake development. An increase of the excitation amplitude is associated with a narrowing of the wake and diminishment of the length scales and coherence of the organized structures for both Reynolds numbers examined.

For the cases investigated, an increase of the excitation amplitude is found to have a broadly similar effect on flow characteristics to that produced due to an increase of the chord Reynolds number. Apart from its physical significance, this similarity can be used in the design and application of separation flow control with periodic excitation to estimate the effect on airfoil performance.

\section{Acknowledgments}

The authors gratefully acknowledge the Natural Sciences and Engineering Research Council of Canada (NSERC) for funding of this work.

\section{References}

[1] Carmichael, B. H., "Low Reynolds number airfoil survey,” NASA Contractor Report No. 165803, Vol. I., Nov. 1981.

[2] Greenblatt, D., and Wygnanski, I. J., "The Control of Flow Separation by Periodic Excitation,” Progress in Aerospace Sciences, Vol. 36, 2000, pp. 487-545.

[3] Collins, F. G., and Zelenevitz, J., "Influence of Sound upon Separated Flow Over Wings," AIAA Journal, Vol. 13, No. 3, 1975, pp. 408-410.

[4] Zaman, K. B. M. Q., "Effect of Acoustic Excitation on Stalled Flows Over an Airfoil,” AIAA Journal, Vol. 30, No. 6, 1992, pp. 1492-1499.

[5] Nishioka, M., Asai, M., and Yoshida, S., “Control of Flow Separation by Acoustic Excitation,” AIAA Journal, Vol. 28, No. 11, 1990, pp. 1909-1915.

[6] Zaman, K. B. M. Q., and McKinzie D. J., "Control of Laminar Separation over Airfoils by Acoustic Excitation," AIAA Journal, Vol. 29, No. 7, 1991, pp. 1075-1083.

[7] Zaman, K. B. M. Q., Bar-Sever, A. and Mangalam, S. M., "Effect of Acoustic Excitation on the Flow over a Low-Re Airfoil," Journal of Fluid Mechanics, Vol. 182, 1987, pp. 127-148. 
[8] Yarusevych. S., Sullivan, P. E., and Kawall, J. G., "Airfoil Boundary Layer Separation and Control at Low Reynolds Numbers," Experiments in Fluids, Vol. 38, No. 4, 2005, pp. 545- 547.

[9] Yarusevych, S., Kawall, J. G., and Sullivan, P. E., "Airfoil Performance at Low Reynolds Numbers in the Presence of Periodic Disturbances," ASME Journal of Fluids Engineering, Vol. 128, No. 3, 2006, pp. 587-595.

[10] Ahuja, K. K., and Burrin, R. H., “Control of Flow Separation by Sound,” AIAA Paper 84-2298, Oct. 1984.

[11] Hsiao, F. B., Jih, J. J., and Shyu, R. N., "The Effect of Acoustics on Flow Passing a High-AOA Airfoil," Journal of Sound and Vibration, Vol. 199, No. 2, 1997, pp .177-178.

[12] Chang, R. C., Hsiao, F. B., and Shyu, R. N., "Forcing Level Effect of Internal Acoustic Excitation on the Improvement of Airfoil Performance,” Journal of Aircraft, Vol. 29, No. 5, 1992, pp. 823-829

[13] Dovgal, A. V., Kozlov, V. V., and Michalke, A., "Laminar Boundary Layer Separation: Instability and Associated Phenomena," Progress in Aerospace Sciences, Vol. 30, 1994, pp. 61-94.

[14] Dovgal, A. V., and Boiko, A. V., "Effect of Harmonic Excitation on Instability of a Laminar Separation Bubble on an Airfoil," Laminar-Turbulent Transition, edited by. H. F. Fasel and W. S. Saric, Springer-Verlag, Berlin, 1999, pp. 675-680.

[15] Boiko, A. V., Grek, G. R., Dovgal, A. V., and Kozlov V. V., "Transition to Turbulence in Separation Bubbles," The Origin of Turbulence in Near Wall Flows, $1^{\text {st }}$ ed., Springer-Verlag, Berlin, 2002, pp. 167-197.

[16] Kawall, J. G., Shokr, M., and Keffer, J. F. "A Digital Technique for the Simultaneous Measurements of Streamwise and Lateral Velocities in Turbulent Flows," Journal of Fluid Mechanics, Vol. 133, 1983, pp. 83-112.

[17] Yarusevych, S., Sullivan, P. E., and Kawall, J. G. "Coherent Structures in Airfoil Boundary Layer and Wake at Low Reynolds Numbers," Physics of Fluids, Vol. 18, No. 4, 044101, 2006, pp. 1-11.

[18] Tani, I., "Low Speed Flows Involving Bubble Separations," Progress in Aerospace Sciences, Vol. 5, 1964, pp. 70-103.

[19] Mueller, T. J. and Batill, S. M. "Experimental Studies of Separation on a Two-Dimensional Airfoil at Low Reynolds Numbers," AIAA Journal, Vol. 20, No. 4, 1982, pp. 457-464.

[20] Sheldahl, R. E., and Klimas, P. C., “Aerodynamic Characteristics of Seven Symmetrical Airfoil Sections Through 180-degree Angle of Attack for Use in Aerodynamic Analysis of Vertical Axis Wind Turbines," Sandia National Laboratories, SAND80-2114, March 1981.

[21] Haggmark, C. P., Bakchinov, A. A., and Alfredsson P. H., "Experiments on a Two-Dimensional Laminar Separation Bubble," Philosophical Transactions of the Royal Society A, Vol. 358, No. 1777, 2000, pp. 3193-3205. 


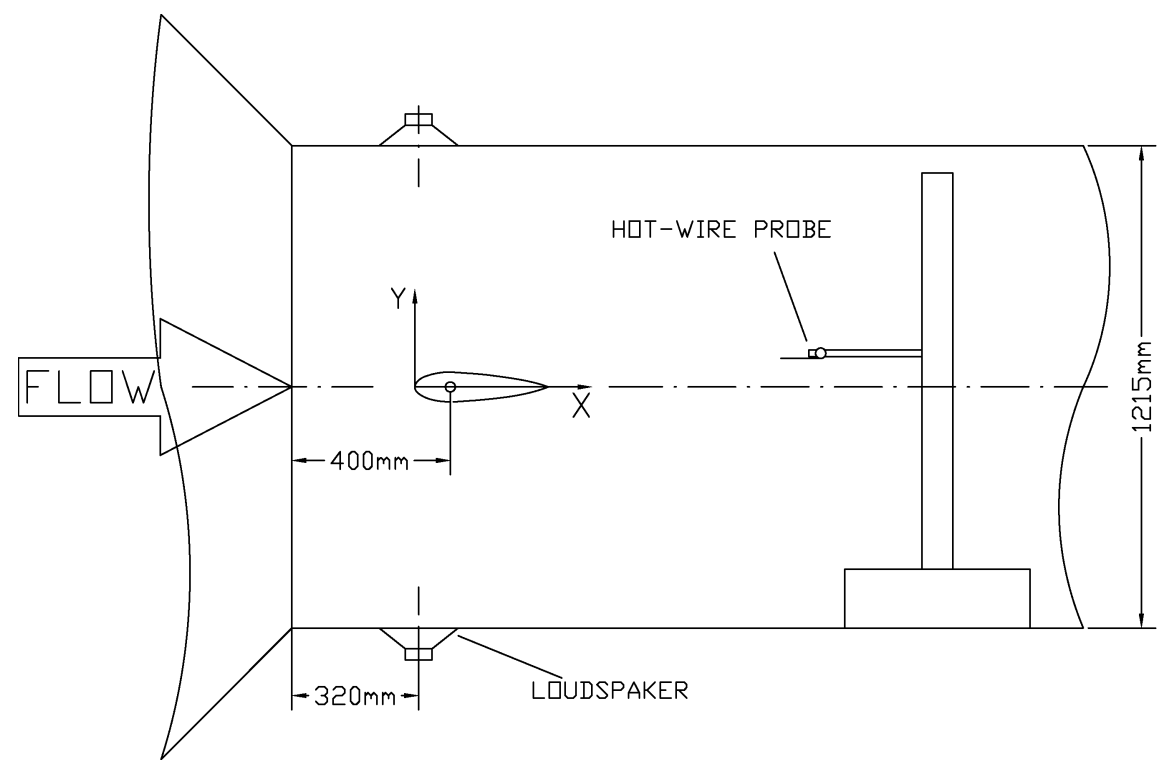

Fig. 1 Test section.

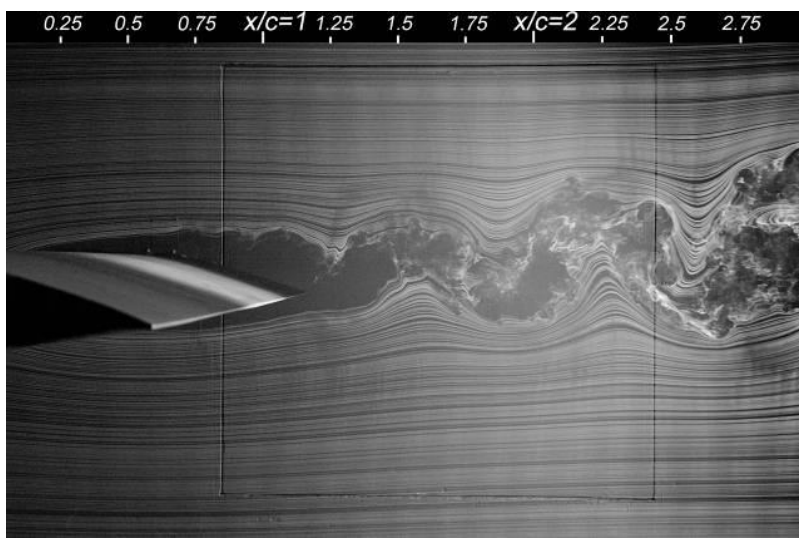

a)

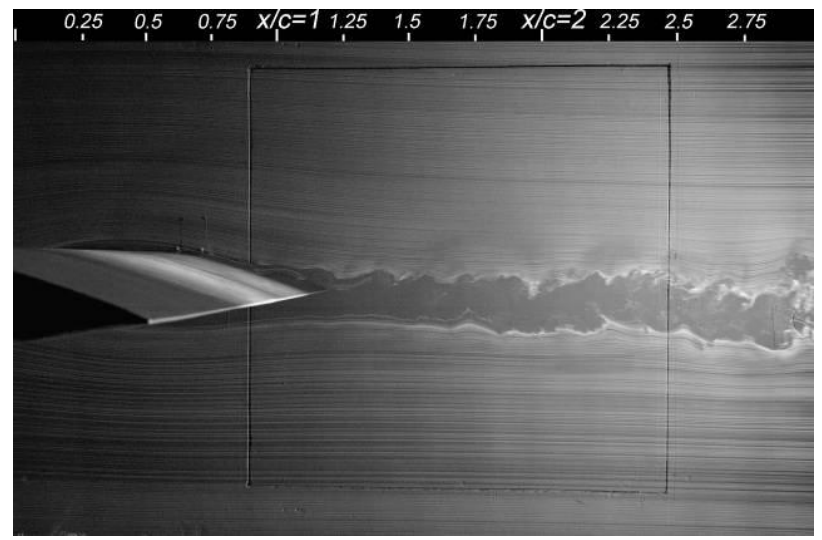

b)

Fig. 2 Flow visualization at $\alpha=5^{\circ}$ for a) $\operatorname{Re}_{c}=100 \times 10^{3}$ and $\left.b\right) \operatorname{Re}_{c}=150 \times 10^{3}$. 


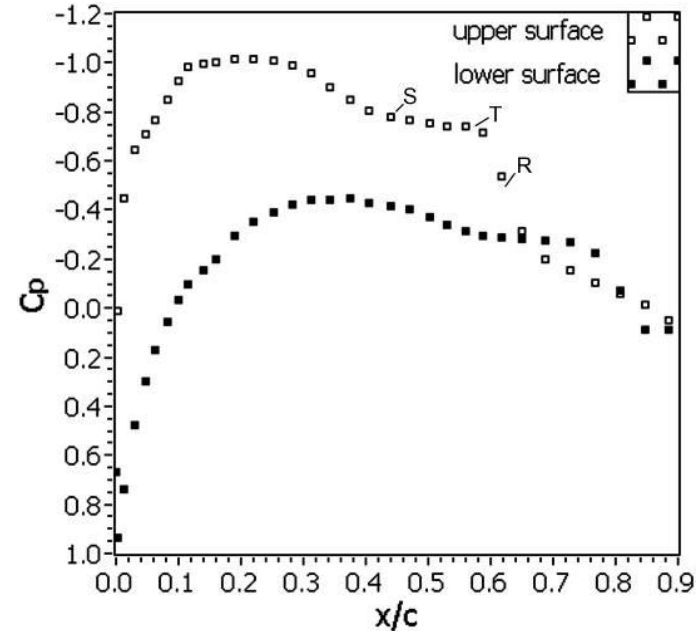

a) $\operatorname{Re}_{\mathrm{c}}=200 \times 10^{3}$

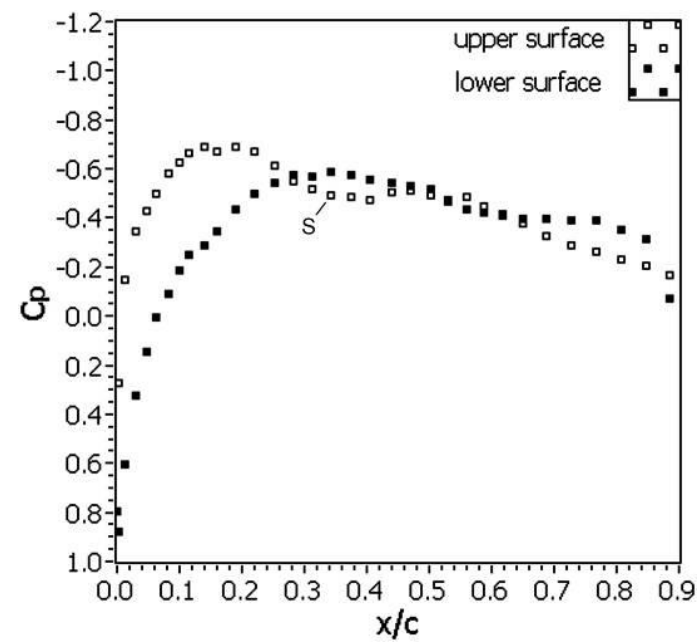

c) $\operatorname{Re}_{\mathrm{c}}=143 \times 10^{3}$

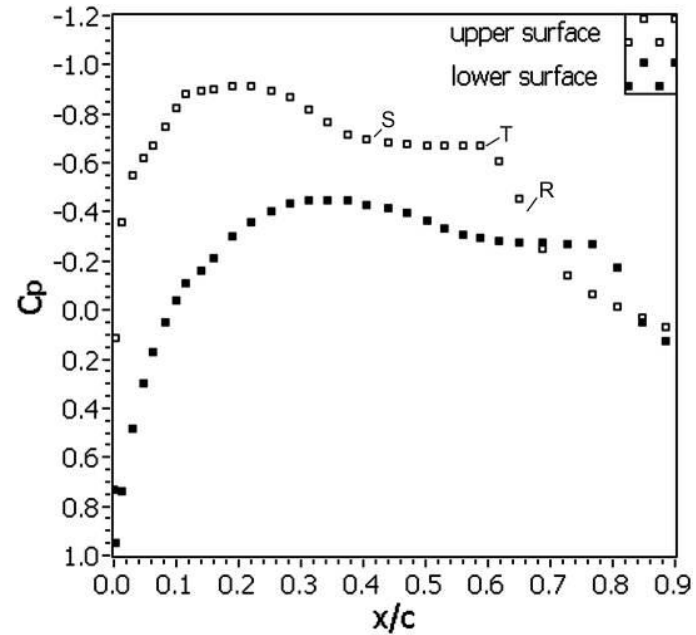

b) $\operatorname{Re}_{\mathrm{c}}=150 \times 10^{3}$

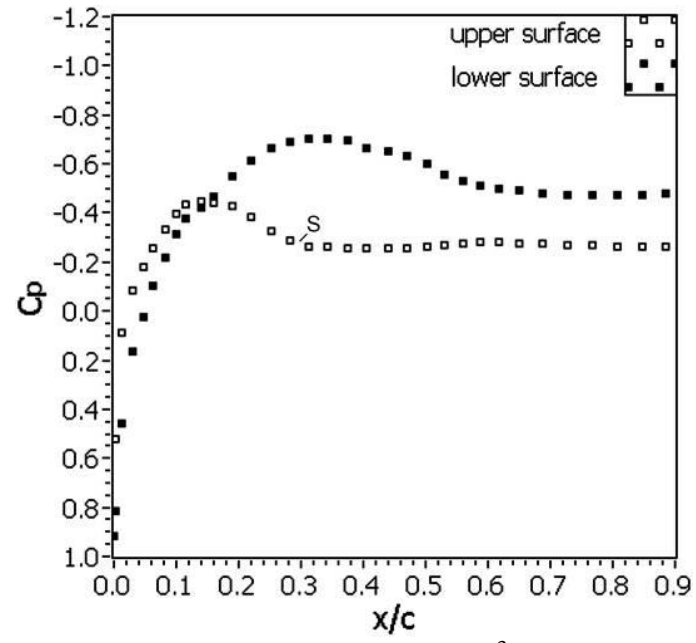

d) $\operatorname{Re}_{\mathrm{c}}=100 \times 10^{3}$

Fig. 3 Reynolds number effect on surface pressure distribution at $\alpha=5^{\circ} . S, R$, and $T$ mark separation, transition and reattachment. When separated shear layer does not reattach, only the location of separation is shown. 


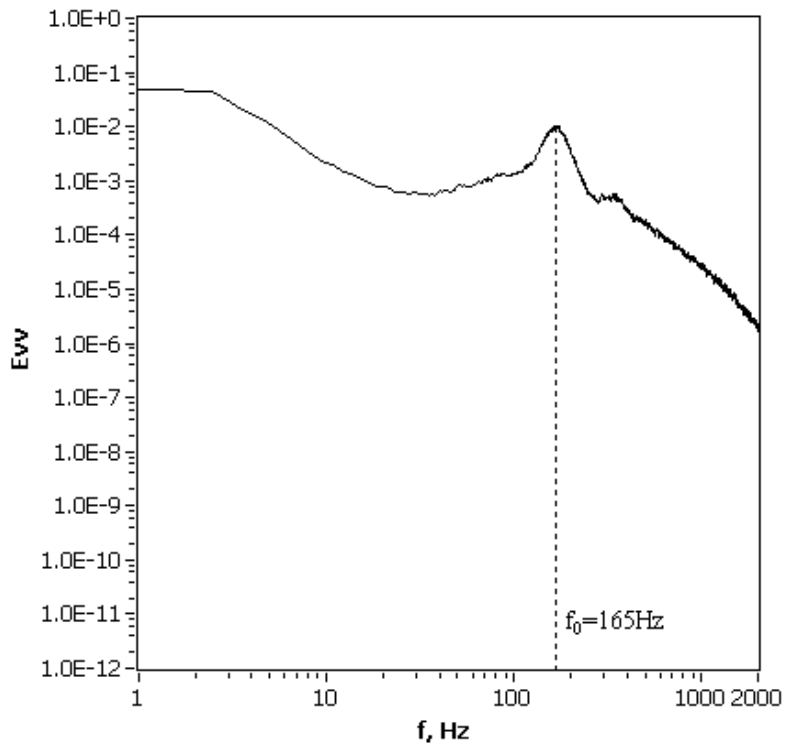

a) $\operatorname{Re}_{\mathrm{c}}=100 \times 10^{3}, \mathrm{x} / \mathrm{c}=0.47$

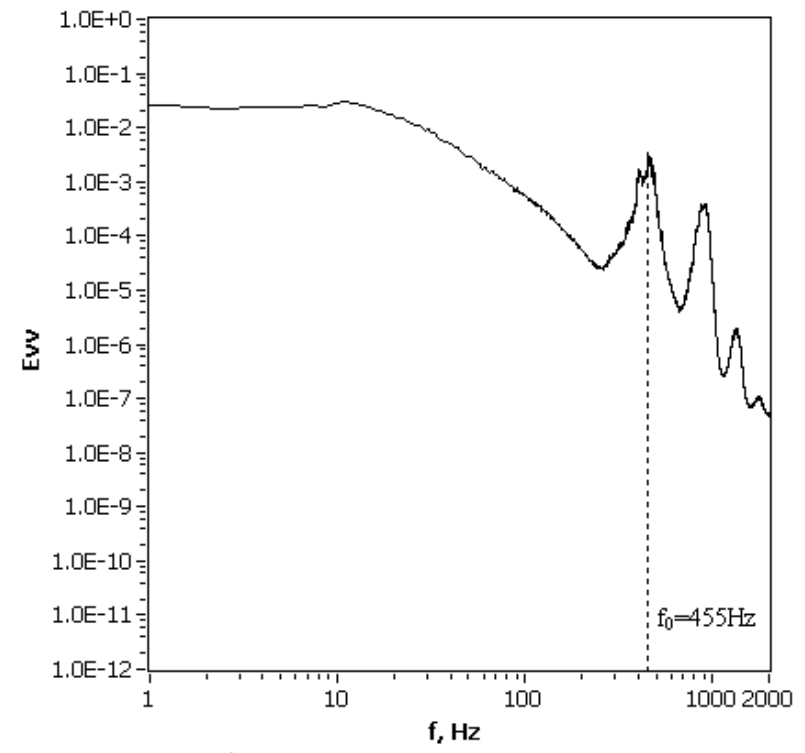

b) $\operatorname{Re}_{\mathrm{c}}=150 \times 10^{3} \mathrm{x} / \mathrm{c}=0.53$

Fig. 4 Spectra of the vertical velocity component $\left(E_{v v}\right)$ pertaining to the separated shear layer at $\alpha=5^{\circ}$.

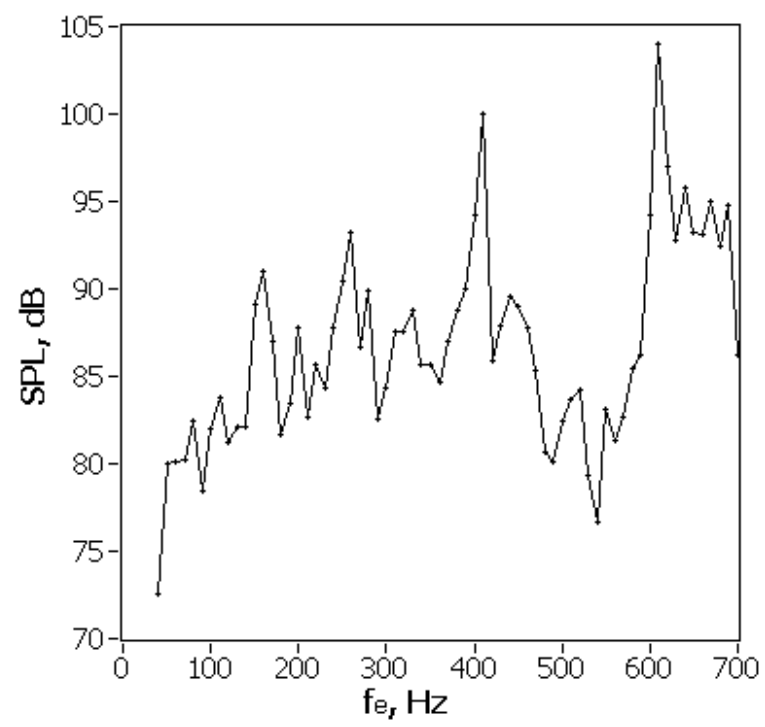

Fig. 5 Test section resonance characteristics. 


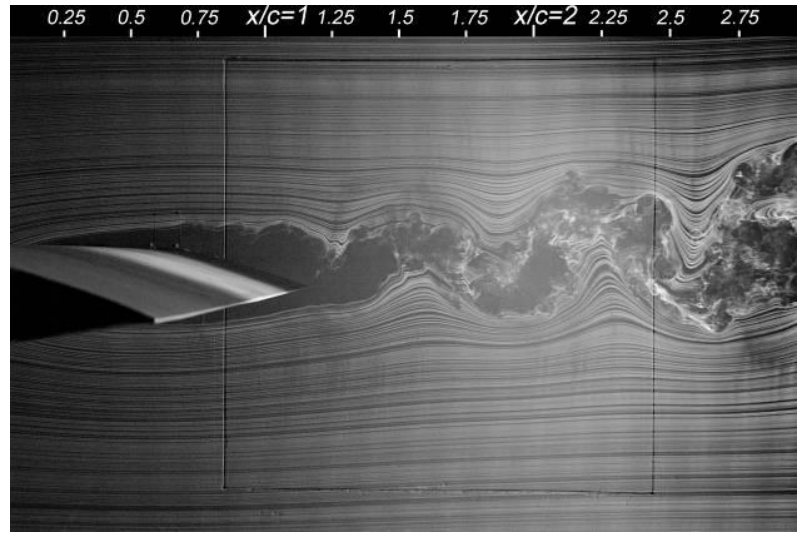

a) no control

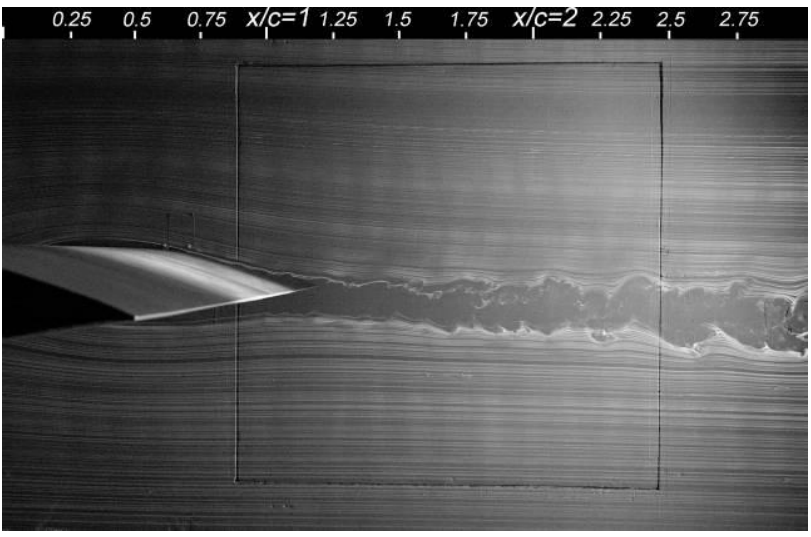

b) control: $\mathrm{f}_{\mathrm{e}}=165 \mathrm{~Hz}, \mathrm{SPL}=105 \mathrm{~dB}$

Fig. 6 Effect of acoustic excitation for $\operatorname{Re}_{c}=100 \times 10^{3}$ at $\alpha=5^{\circ}$.

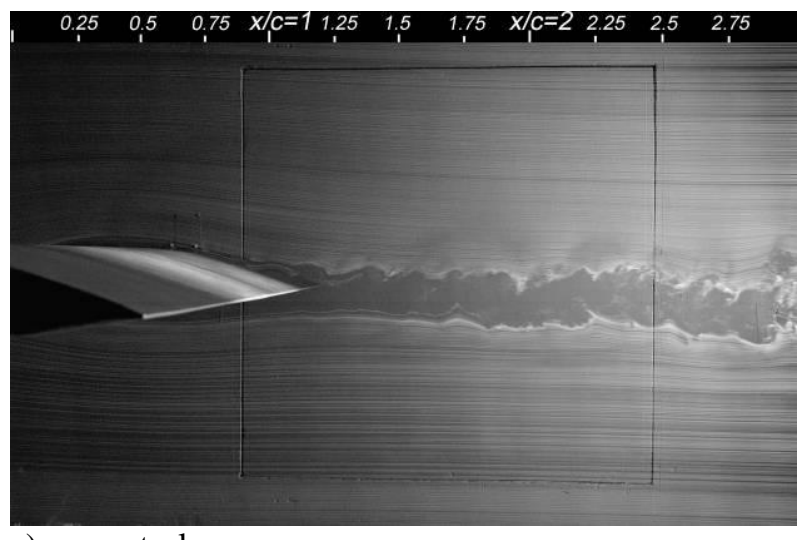

a) no control

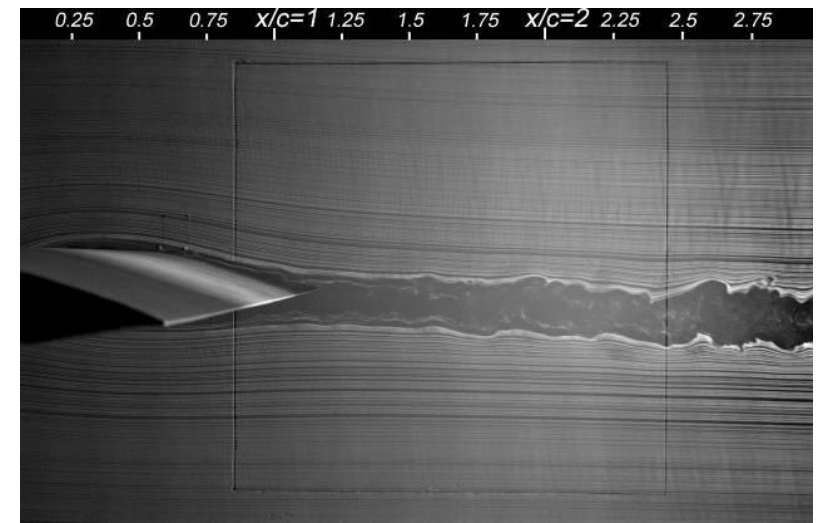

b) control: $\mathrm{f}_{\mathrm{e}}=455 \mathrm{~Hz}, \mathrm{SPL}=106 \mathrm{~dB}$

Fig.7 Effect of acoustic excitation for $\operatorname{Re}_{c}=150 \times 10^{3}$ at $\alpha=5^{\circ}$. 


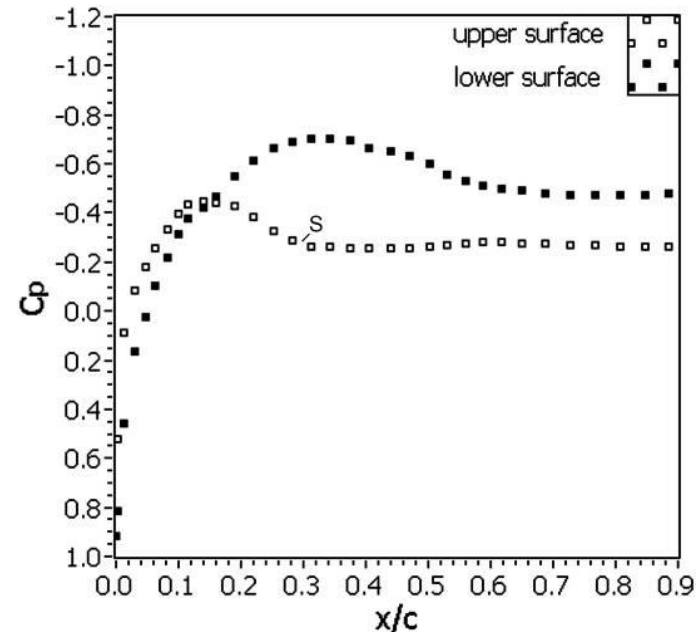

a) no control (70.4 $\mathrm{dB}$ noise)

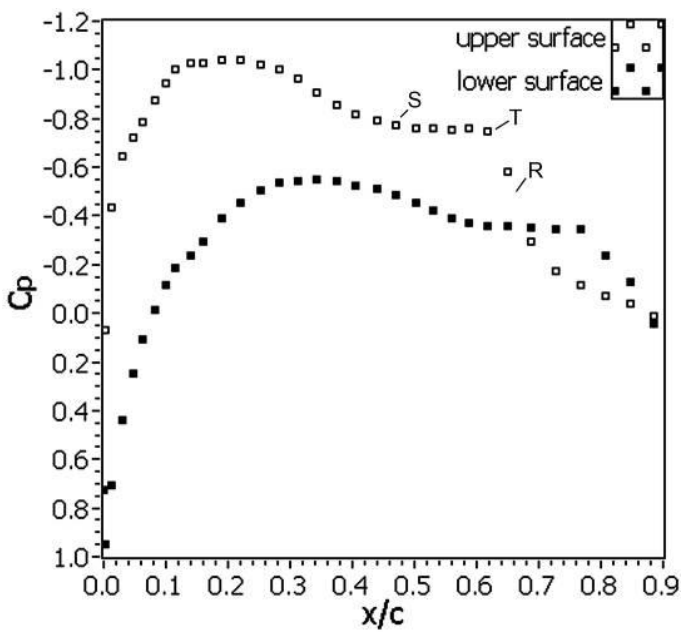

c) $94.3 \mathrm{~dB}$

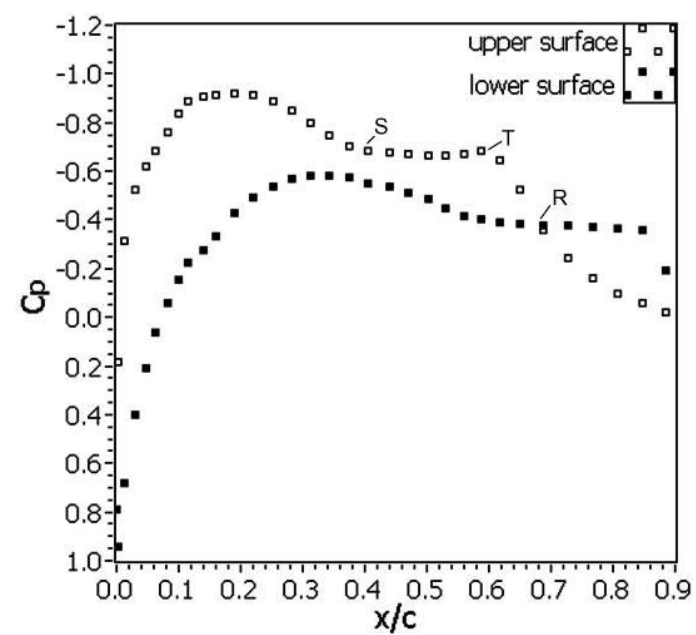

b) $80.1 \mathrm{~dB}$

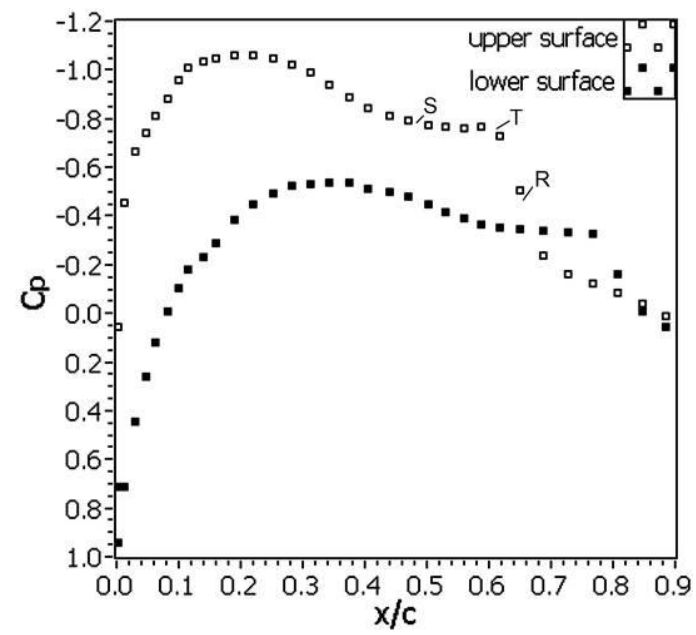

d) $104 \mathrm{~dB}$

Fig. 8 Effect of excitation amplitude on surface pressure distributions for $\operatorname{Re}_{\mathrm{c}}=100 \times 10^{3}, \alpha=5^{\circ} . \mathrm{S}, \mathrm{R}$, and $\mathrm{T}$ mark separation, transition and reattachment. When separated shear layer does not reattach, only the location of separation is shown. 


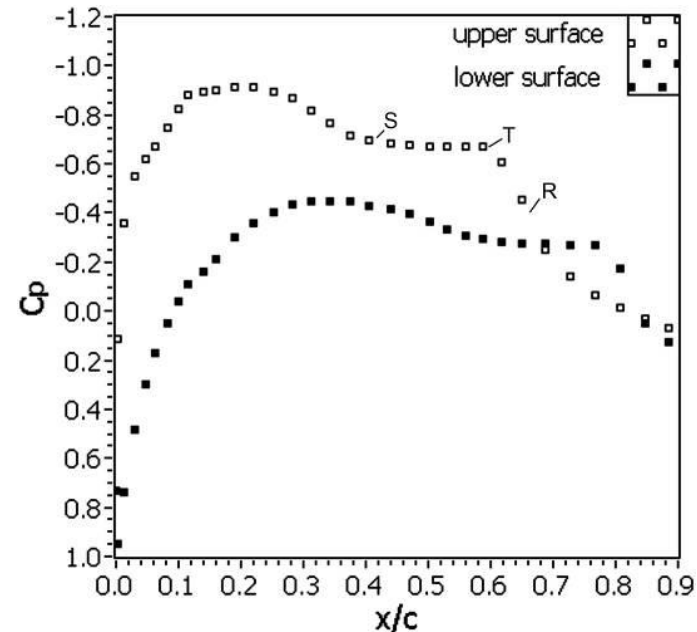

a) no control (72.6 dB noise)

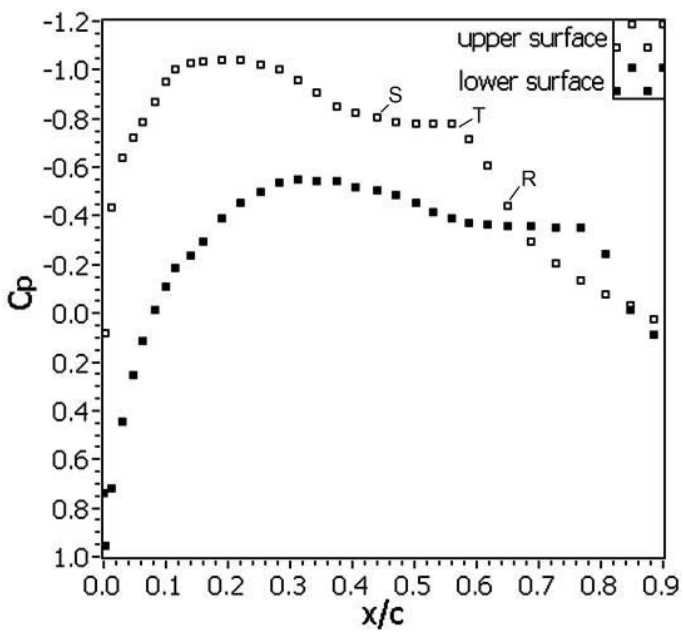

c) $96.1 \mathrm{~dB}$

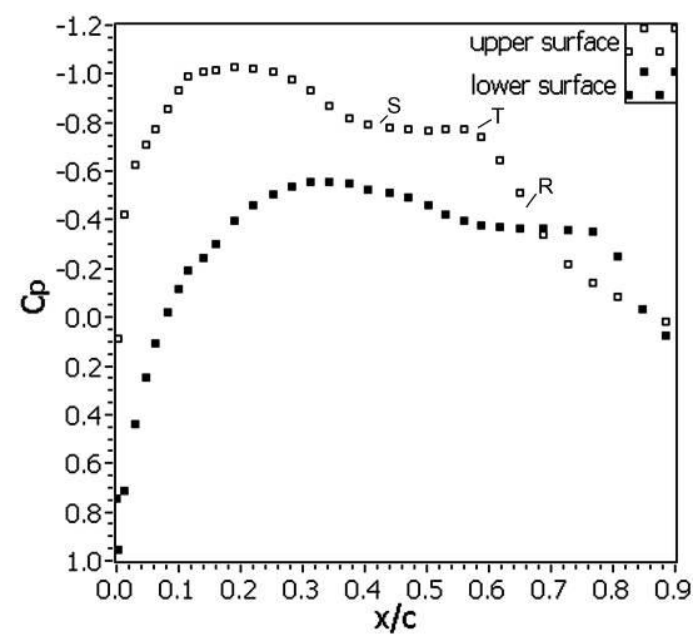

b) $81.6 \mathrm{~dB}$

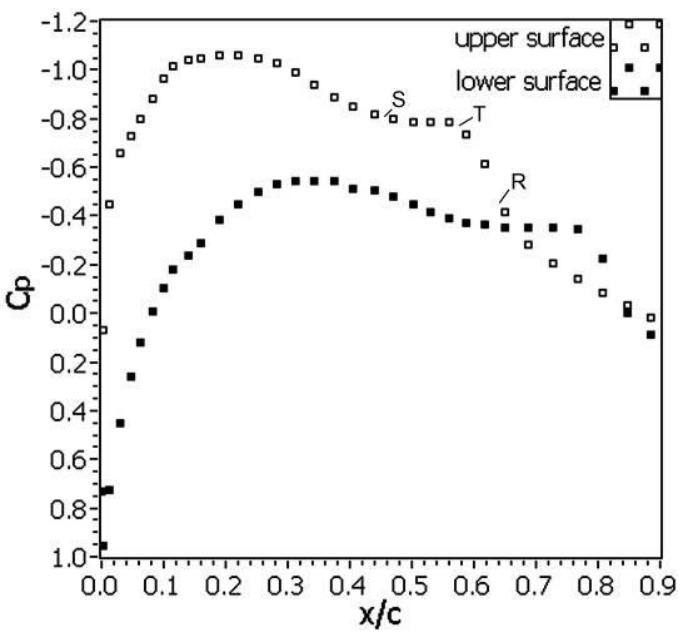

d) $106.2 \mathrm{~dB}$

Fig. 9 Effect of excitation amplitude on surface pressure distributions for $\operatorname{Re}_{c}=150 \times 10^{3}, \alpha=5^{\circ}$. $S$, $R$, and $T$ mark separation, transition and reattachment.
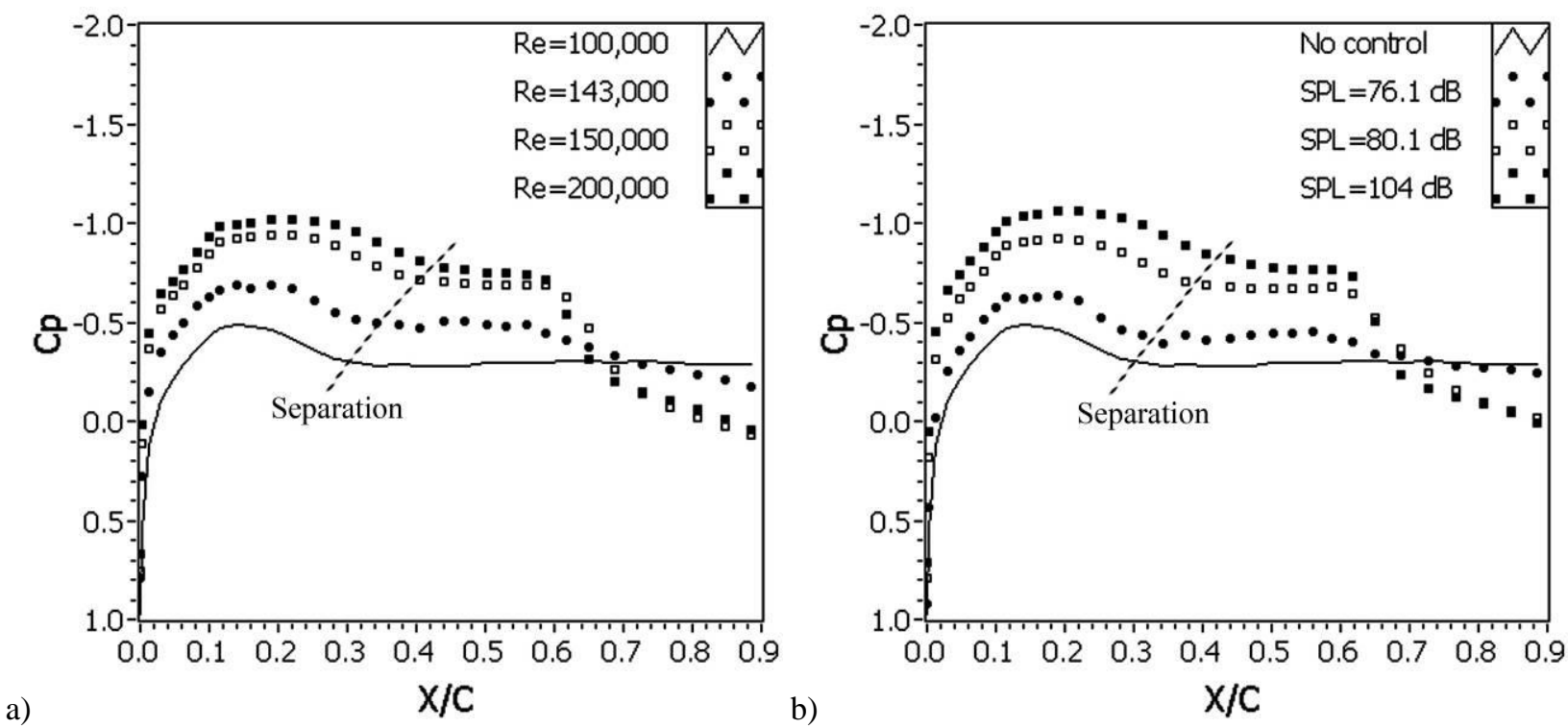

Fig. 10 Upper surface pressure distributions at $\alpha=5^{\circ}$ a) effect of Reynolds number and b) effect of excitation amplitude for $\operatorname{Re}_{\mathrm{c}}=100 \times 10^{3}$. Dashed lines mark the estimated locations of separation. 

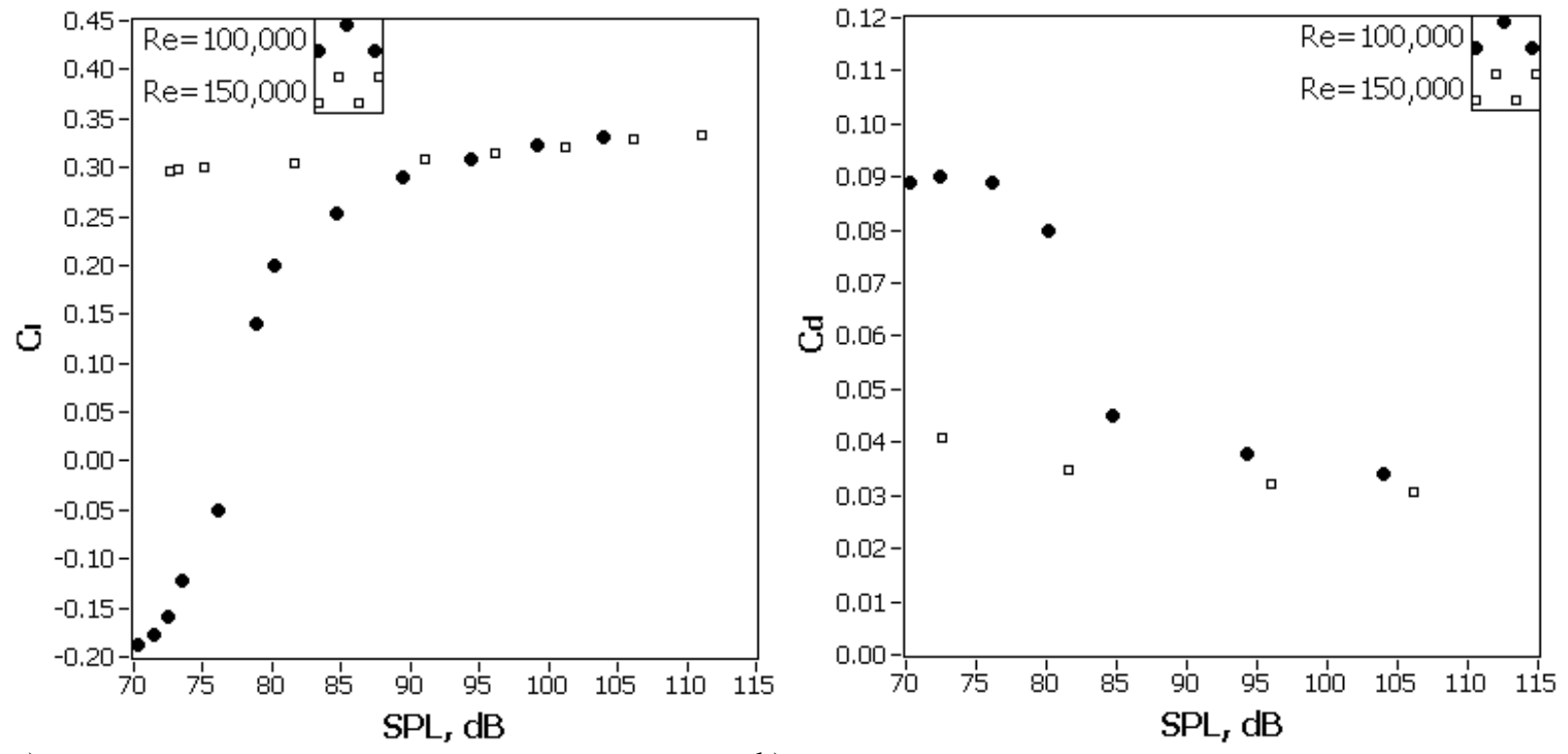

a)

b)

Fig. 11 Variation of a) airfoil lift coefficient $\left(C_{l}\right)$ and b) airfoil drag coefficient $\left(C_{d}\right)$ with excitation amplitude at $\alpha=5^{\circ}$.

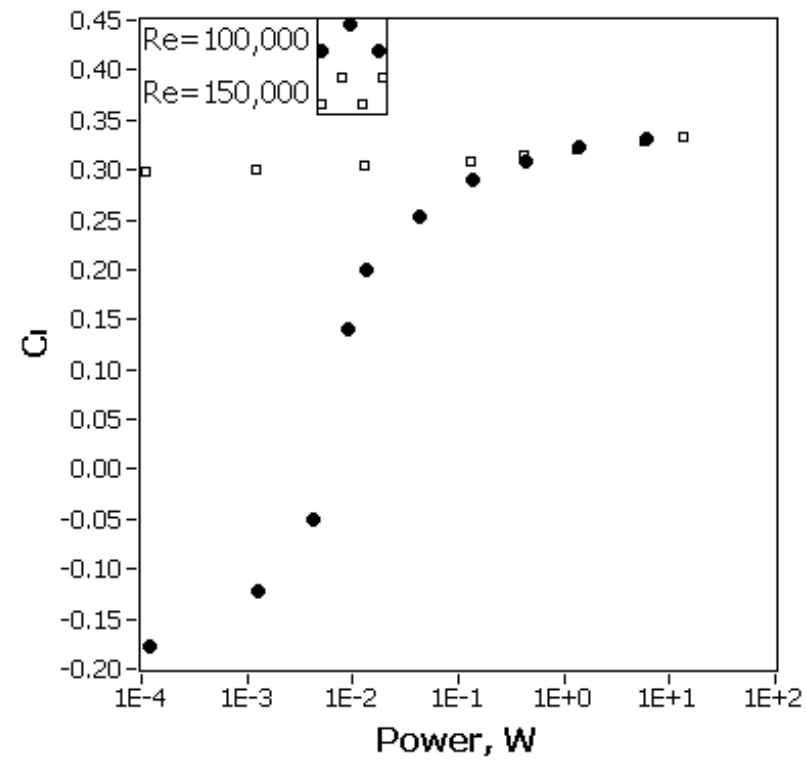

Fig. 12 Variation of airfoil lift coefficient with the electric power input at $\alpha=5^{\circ}$. 


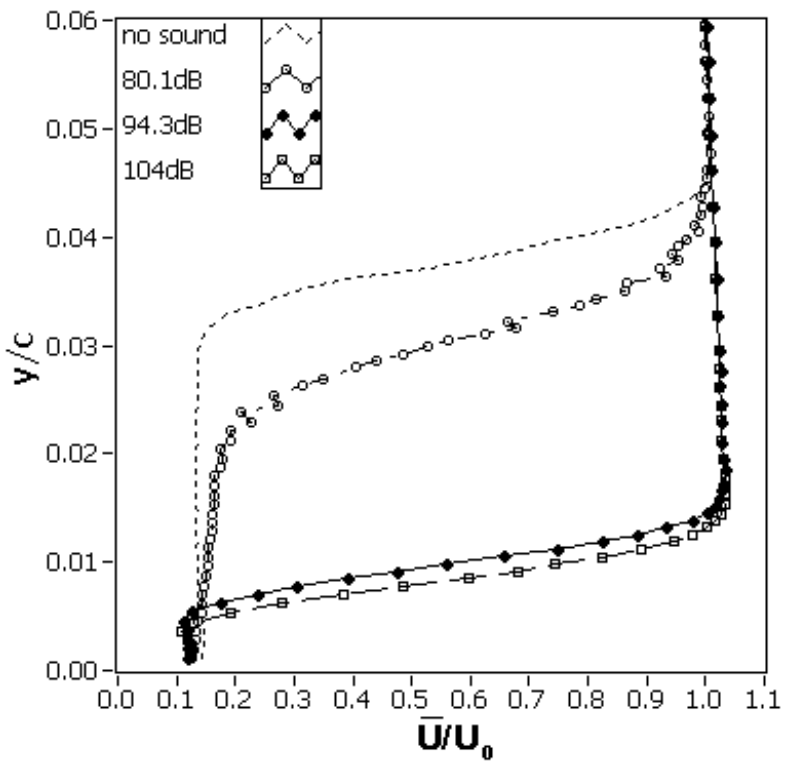

a)

Fig. 13 Effect of excitation amplitude on a) mean and b) RMS boundary layer profiles for $\operatorname{Re}_{c}=100 \times 10^{3}, \alpha=5^{\circ}$, and $\mathrm{x} / \mathbf{c}=\mathbf{0 . 4 7}$.

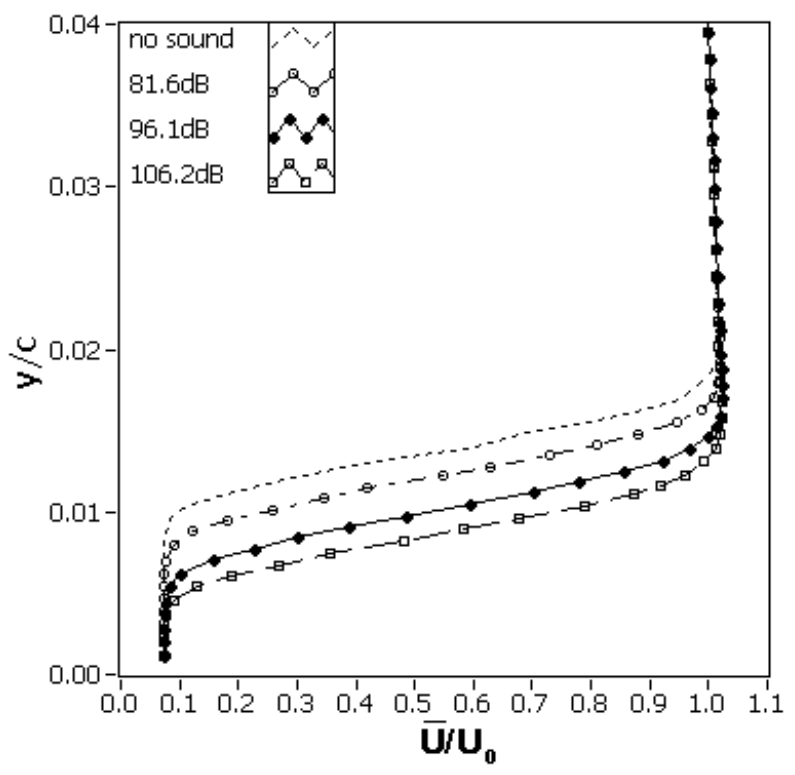

a)

Fig. 14 Effect of excitation amplitude on a) mean and b) RMS boundary layer profiles for $\operatorname{Re}_{c}=150 \times 10^{3}, \alpha=5^{\circ}$, and $\mathbf{x} / \mathbf{c}=\mathbf{0 . 5}$.

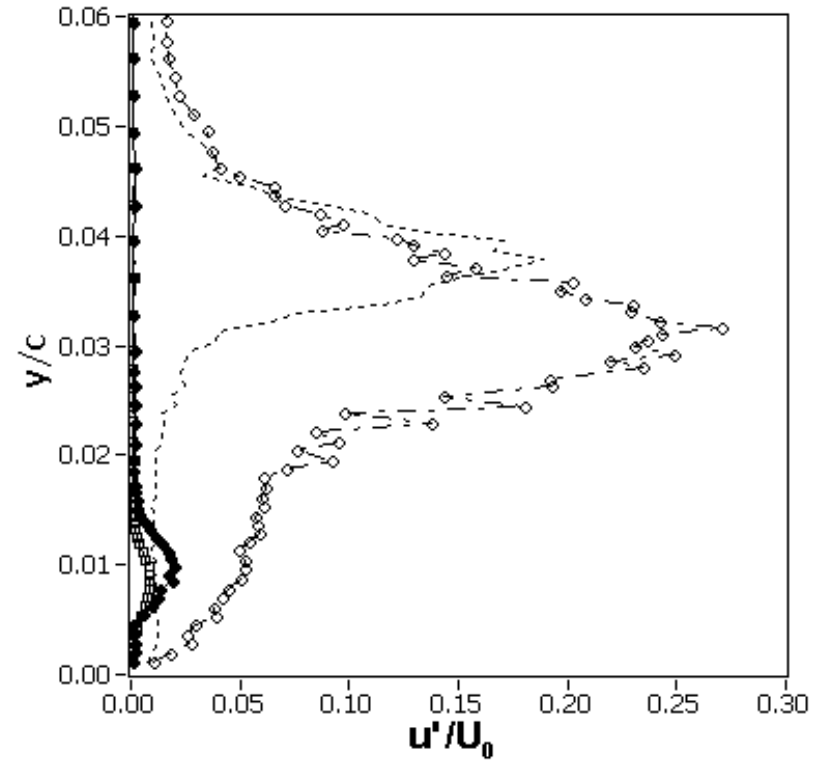

b)

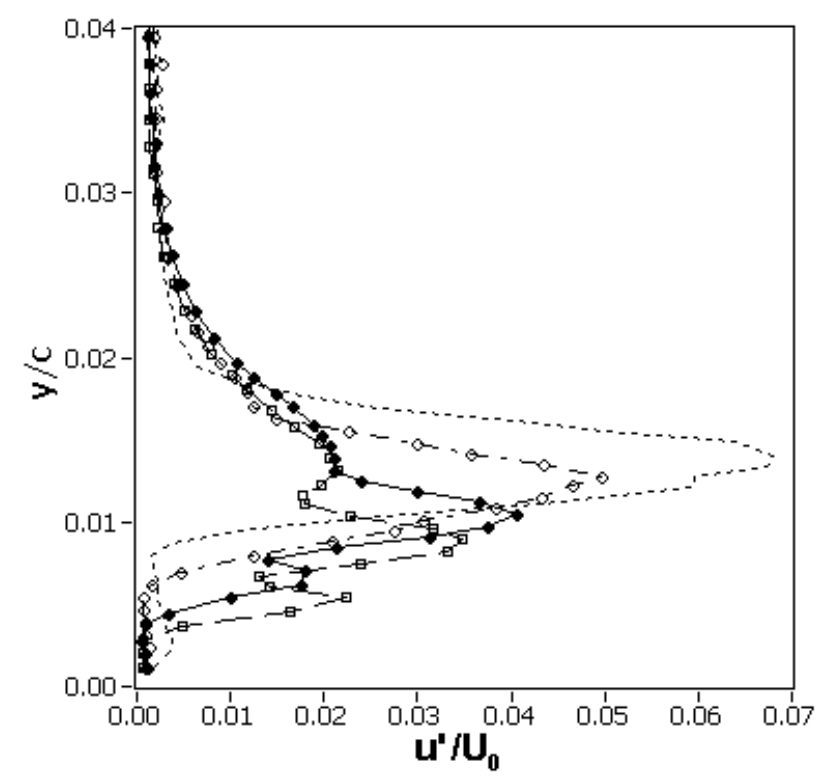

b) 


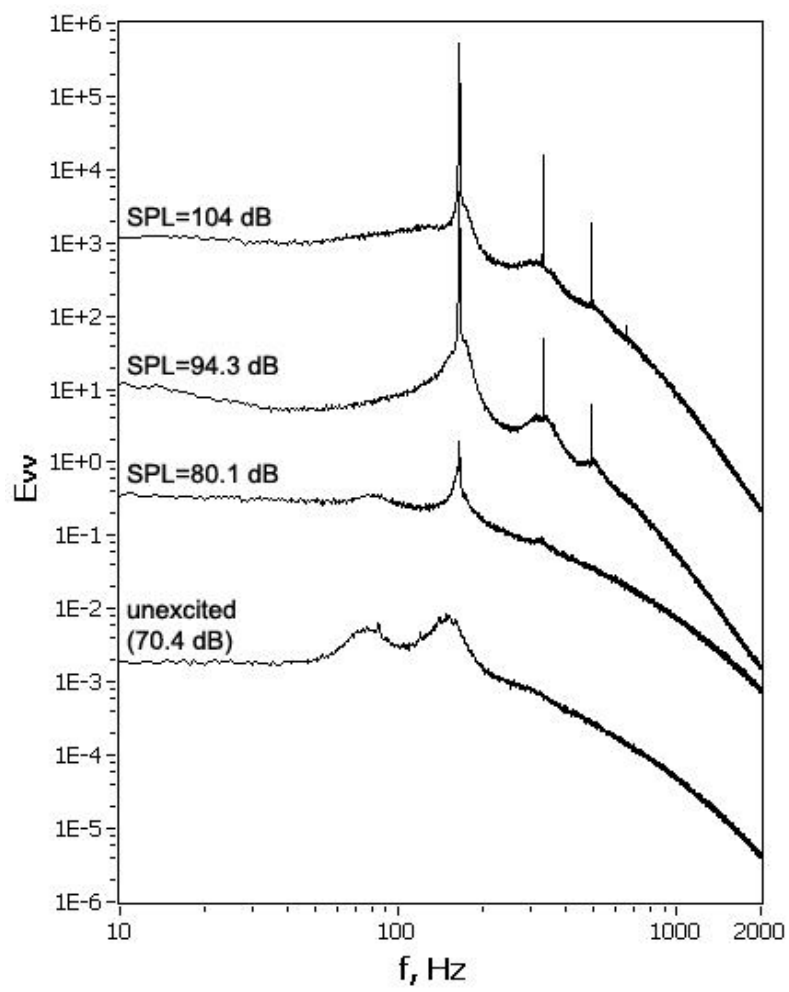

a)

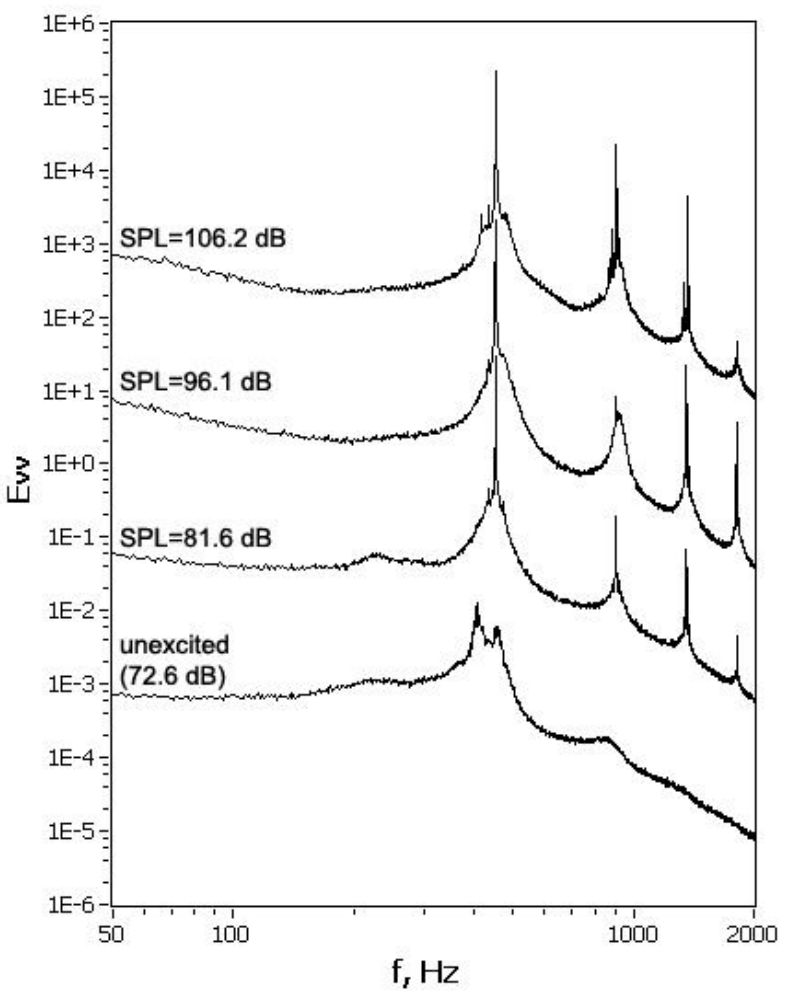

b)

Fig. 15 Effect of excitation amplitude on boundary layer velocity spectra for a) $R_{c}=100 \times 10^{3}$ and $\left.b\right) R_{c}=150 \times 10^{3}$ at $\alpha=5^{\circ}, \mathrm{x} / \mathrm{c}=\mathbf{0 . 5 9}$. Measurements were conducted at $\mathrm{y} / \mathrm{c}$ positions corresponding to $0.5 \mathrm{U}_{0}$. The amplitude of each successive spectrum is stepped by two orders of magnitude.

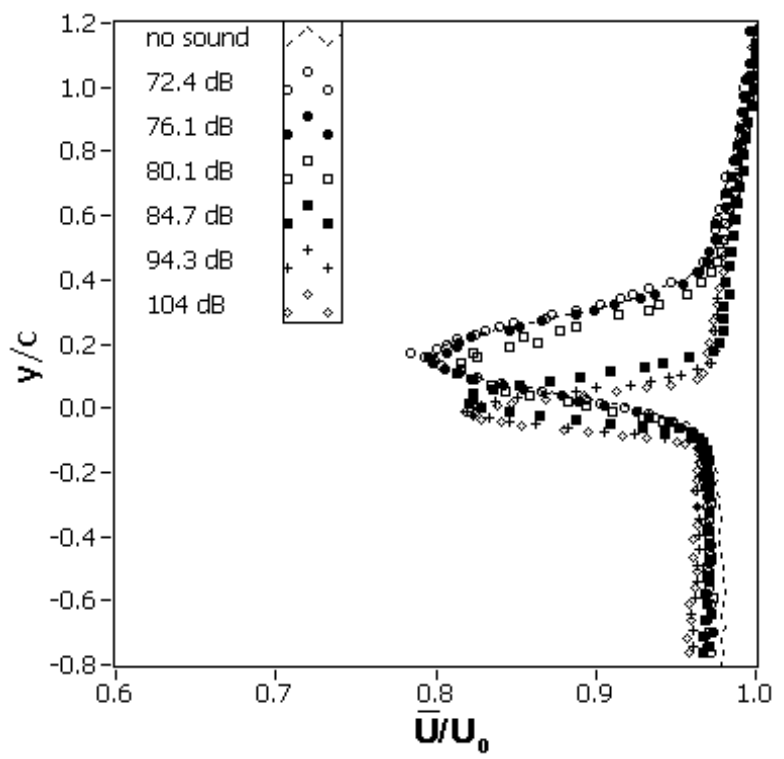

a)

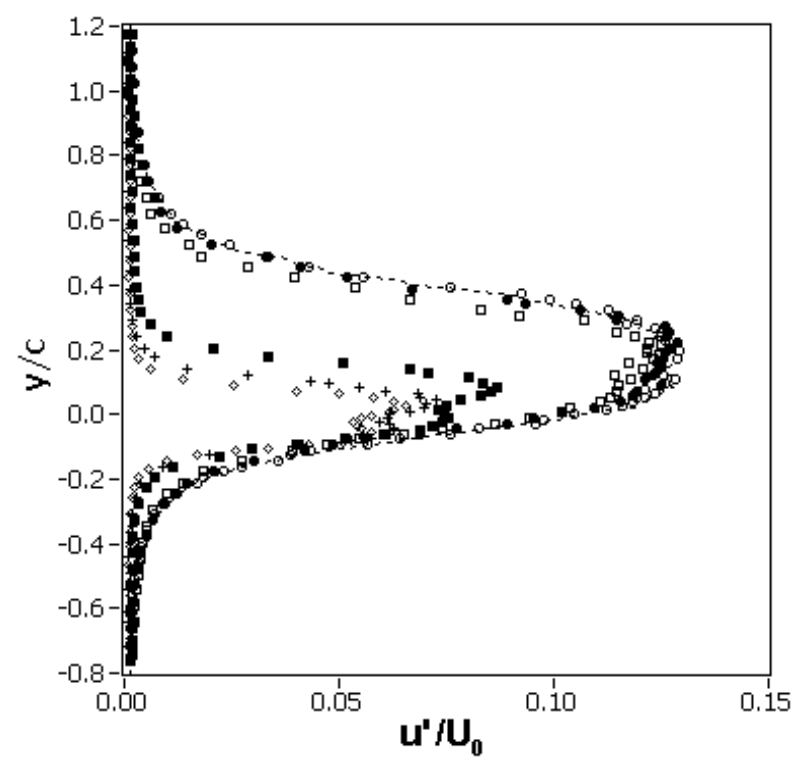

b)

Fig. 16 Effect of excitation amplitude on a) mean and b) RMS wake profiles for $\operatorname{Re}_{c}=100 \times 10^{3}, \alpha=5^{\circ}$, and $x / c=2$. 


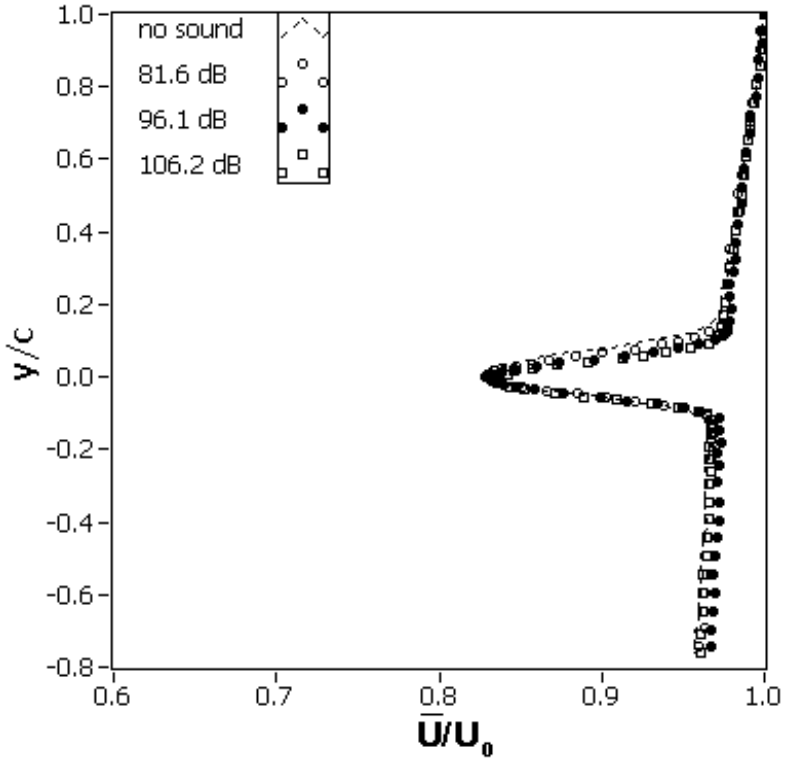

a)

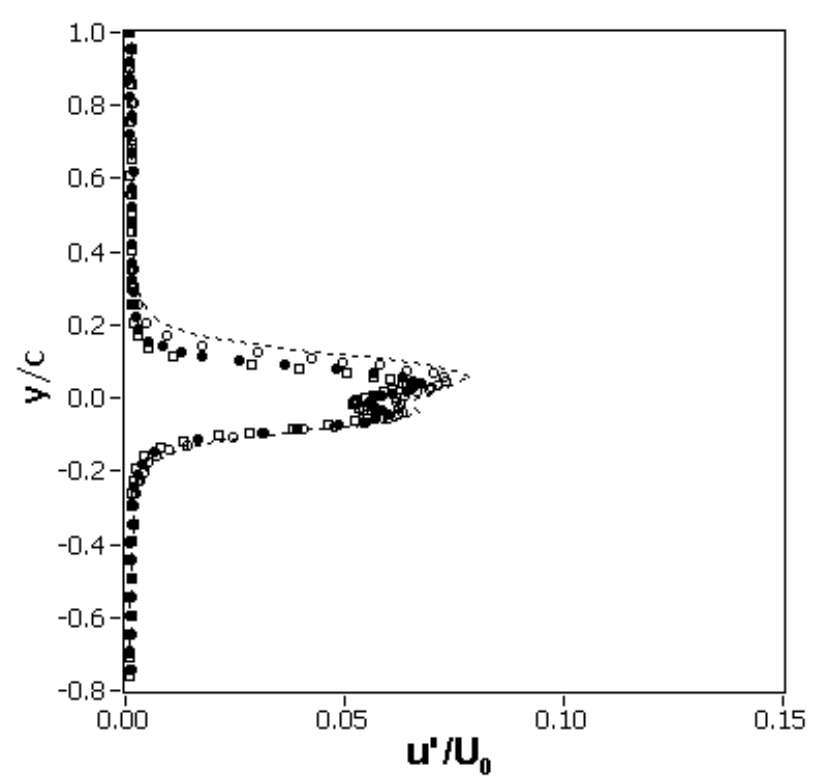

b)

Fig. 17 Effect of excitation amplitude on a) mean and b) RMS wake profiles for $\operatorname{Re}_{c}=150 \times 10^{3}, \alpha=5^{\circ}, x / c=2$.

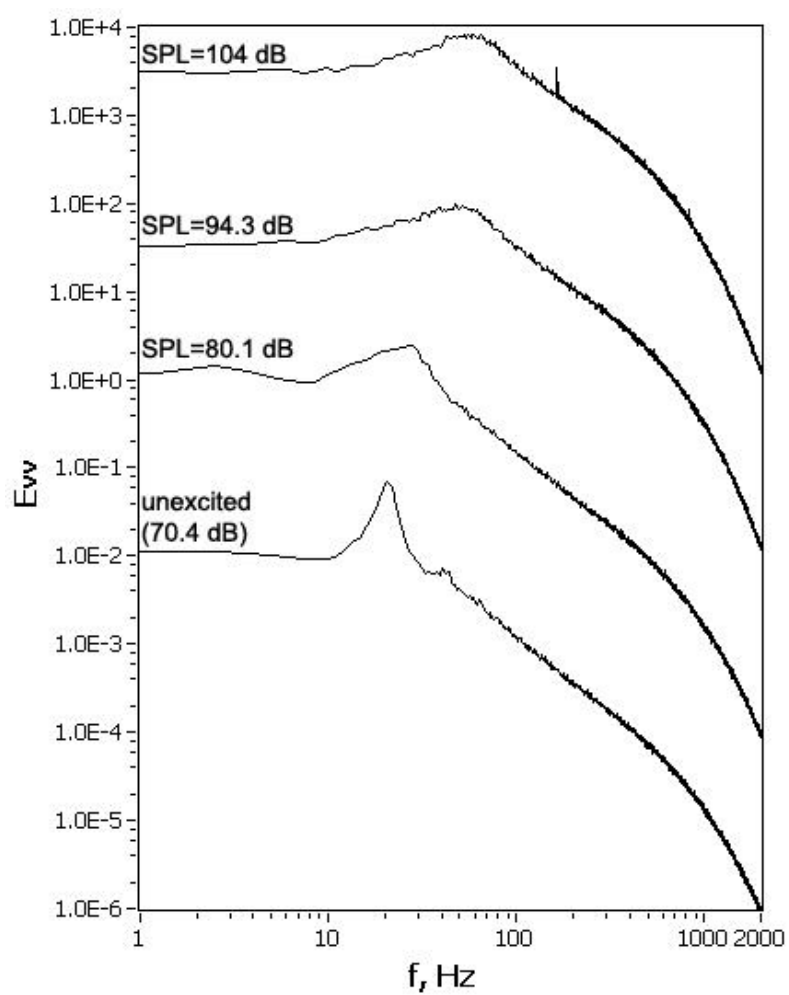

a)

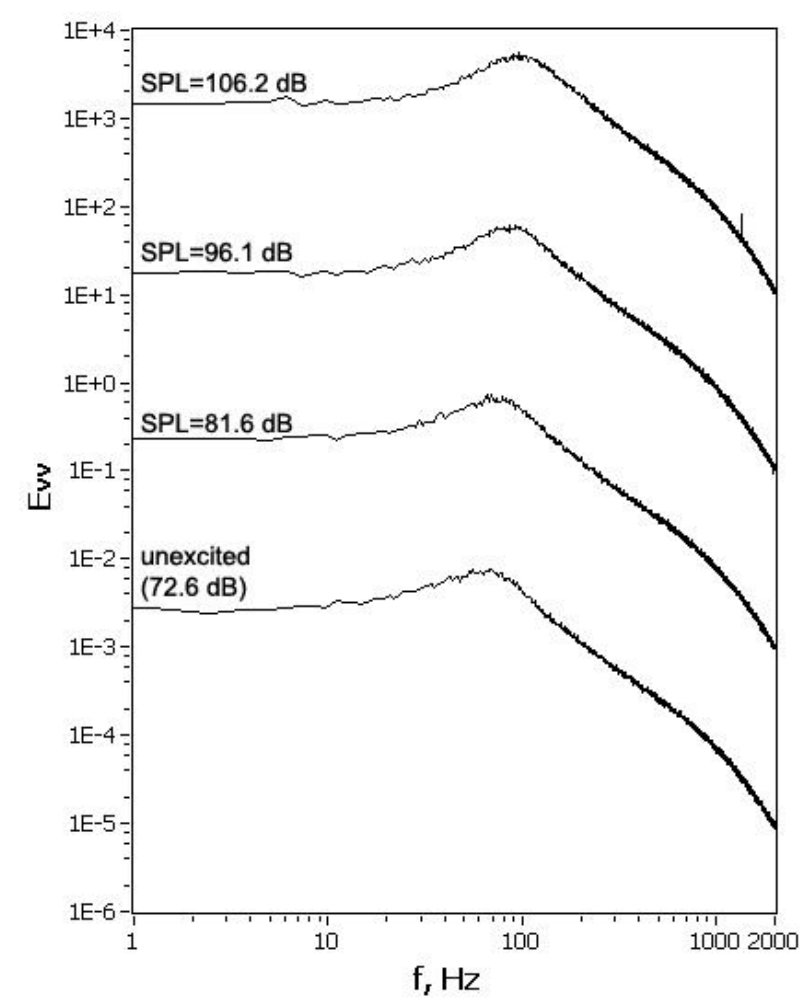

b)

Fig. 18 Effect of excitation amplitude on wake velocity spectra for a) $R_{c}=100 \times 10^{3}$ and $\left.b\right) R_{c}=150 \times 10^{3}$ at $\alpha=5^{\circ}$, $x / c=2$. Measurements were conducted at $y / c$ positions corresponding to half of the maximum velocity deficit. The amplitude of each successive spectrum is stepped by one order of magnitude. 